\title{
Modification of a Linear Bar-Trough System by a Standing Edge Wave
}

\author{
BERNARD O. BAUER ${ }^{1}$ and BRIAN GREENWOOD ${ }^{2}$ \\ ${ }^{1}$ Department of Geography, University of Southern California, Los Angeles, CA 90089-0255 (U.S.A.) \\ ${ }^{2}$ Departments of Geography and Geology, University of Toronto, Scarborough Campus, Scarborough, Ont. M1C 1A4 \\ (Canada)
}

(Received August 8, 1989; revision accepted November 30, 1989)

\begin{abstract}
Bauer, B.O. and Greenwood, B., 1990. Modification of a linear bar-trough system by a standing edge wave. Mar. Geol., 92: 177-204.

Detailed fluid motions and bathymetric changes in the lacustrine nearshore zone at Wymbolwood Beach, Georgian Bay, Canada were monitored during storms to test theoretical postulates about the importance of low-frequency wave motions to nearshore circulation of water and sediments. Eighteen continuous-resistance wave staffs and two electromagnetic current meters were deployed along one shore-normal and two shore-parallel instrument arrays over a period of two months. During one intense storm, a mode 3 , standing edge wave at $0.035 \mathrm{~Hz}$ was the predominant lowfrequency motion. Prior to the storm, the bathymetry was characterized by linear bar-trough systems, and during the storm, these features migrated onshore and became rhythmic in response to the length scales and relatively fixed locations of nodal and antinodal lines of the standing edge wave. However, a well-defined crescentic bar, as predicted by the model under the condition of zero net sediment flux divergence, did not evolve because the hydrodynamic forcing ceased before an equilibrium condition could be attained. Nevertheless, the location of scour and accretion features demonstrated the tendency towards such a crescentic form. The offshore and alongshore irregularities of the post-storm bathymetry are not readily explained by alternative hydrodynamic interactions.
\end{abstract}

\section{Introduction}

The configuration of a shoreline is a manifestation of the complex interaction of a variable wave climate with the quantity and types of available beach materials. Incident wave stresses are clearly important to this interaction, but secondary mechanisms of water and sediment circulation are also thought to have a contributing, and potentially dominant, role in nearshore morphodynamics. The low-frequency components of wave fields are particularly relevant because the length scales of long-period waves, unlike incident gravity waves, are of the same order of magnitude as the dimensions of many large coastal features.

Holman and Bowen (1982) proposed a model that incorporated low frequency, edge wave motions, and demonstrated theoretically that the bottom drift patterns associated with complex wave fields looked similar to many commonly observed nearshore topographic features. There can be little doubt as to the existence of edge waves (e.g., Huntley, 1976; Huntley et al., 1981; Katoh, 1981; Oltman-Shay and Guza, 1987), and Bowen and Huntley (1984) point out that there is ample evidence to suggest that "low-frequency motions are dominant over a significant region in the surf zone 
and that this dominance increases in very severe conditions, precisely the conditions in which the most active sediment transport is expected to occur."

Despite the improvement in conceptual understanding of nearshore circulations provided by edge wave theory, there has been very little empirical support for the model of Holman and Bowen (1982). Few studies have been able to monitor morphological changes during storms and relate them convincingly to the time modulation of the long wave field. Furthermore, aside from the recent experiments' at the CERC Field Research Facility at Duck, North Carolina, most comprehensive field experiments have been conducted on planar beaches. Thus, many alternative models of bar evolution and maintenance have recently been re-examined. Stive and Battjes (1985), for example, demonstrated first-order agreement between measured laboratory profiles and a model based on an undertow mechanism. Dally (1987) also favors an undertow hypothesis, and finds scant evidence to support a long-period wave mechanism. Davidson-Arnott and McDonald (1989) present field evidence which suggests that the presence of an undertow very close to the bed is an important control in maintaining the equilibrium of nearshore bars. Boczar-Karakiewicz et al. (1986) showed theoretically that longperiod, incident surface gravity waves in shallow water will be subject to reflective trapping by bottom undulations and a nonlinear resonance will yield positive feedback between the wave form and the growing bar forms. There are limitations to all bar genesis models, and the controversy concerning bar origin remains unresolved because the manner in which nearshore forms evolve in the field has not yet been fully documented, and since scaling problems preclude their complete examination in the laboratory. It is likely that no single model can account for all bar forms, however, the edge wave interaction model of Holman and Bowen (1982) is the most generally applicable because it accommodates both linear and rhythmic topographies coincidentally.
This paper reports the results of a study that was designed to monitor the detailed, threedimensional hydrodynamics and morphodynamics of a barred nearshore zone with particular focus on the low-frequency motions. The nature of the temporal and spatial links between the fluid and sediment systems are discussed, and for the first time, empirical evidence is provided in support of the theoretical constructs of Holman and Bowen (1982).

\section{Background}

One mode of low frequency energy is a trapped or edge wave that propagates parallel to the shoreline. The existence of edge waves was first discussed by Stokes (1846). Eckart (1951) and Ursell (1952) extended the theory and demonstrated that a whole family of edge wave modes could exist on a linearly sloping beach. Their alongshore behaviour is sinusoidal while their offshore behavior is described by a Laguerre polynomial of order $n$, where $n$ is the edge wave integer mode number. Eckart's (1951) solution to the linear shallow water equations for edge waves propagating in the longshore direction $(y)$ for a plane beach takes the following form:

$\Phi_{n}=\frac{\left(a_{n} g\right)}{\sigma} \phi_{n}(x) \mathrm{e}^{i\left(\kappa_{n} y-\sigma t\right)}$

where $\Phi_{n}$ is the velocity potential, $a_{n}$ is the wave amplitude, $\sigma$ is longshore radian frequency $(2 \pi / T), \kappa_{n}$ is longshore wave number $(2 \pi / L), T$ and $L$ are the wave period and wavelength respectively, $g$ is gravitational acceleration, $t$ is time, and $x$ is the horizontal coordinate, positive offshore. The parameter $\phi_{n}(x)$ gives the offshore behavior:

$\phi_{n}(x)=L_{n}\left(2 \kappa_{n} x\right) \mathrm{e}^{-\kappa_{n} x}$

where $L_{n}$ is the Laguerre polynomial of order $n$ which demonstrates the more complex seaward behavior of larger mode numbers. The edge wave described by Stokes was simply the lowest order mode $(n=0)$ which varies sinusoidally alongshore and decays exponentially 
offshore. Ursell (1952) further suggested that a complete edge wave spectrum was possible including both continuous and discrete portions with distinct cutoff frequencies. The edge wave dispersion relation given by Ursell (1952) is:

$\sigma^{2}=g\left|\kappa_{n}\right| \sin \{(2 n+1) \beta\}$

where $\beta$ is beach slope.

The generation of edge waves involves two processes: an initial perturbation or disturbance at a frequency and wave number appropriate to the edge wave dispersion relation, and subsequent excitation of that disturbance with sufficient strength to lead to edge wave growth and maintenance. Initial perturbations are inherent to most natural systems due to pressure fluctuations associated with wind stress and to reflection and refraction of incident waves from headlands and other structures. The excitation and growth of edges waves occurs as a result of nonlinear wavewave interactions leading to resonant amplification of free modes. A triad of waves will interact and exchange energy if the resonance conditions:

$\left.\sigma_{1}+\sigma_{2}=\sigma_{3}\right\}$

$\left.\kappa_{1}+\kappa_{2}=\kappa_{3}\right\}$

are satisfied by the relevant wave dispersion relation (Phillips, 1977). Although the triad mechanism does apply to edge wave generation in theory (Guza and Bowen, 1975, 1976) and reasonable success in reproducing such resonances has been obtained in the laboratory (Guza and Inman, 1975), field substantiation of this interaction has never been documented.

The potential importance of edge waves in nearshore circulation was examined in detail by Bowen (1967, 1969), although others had commented on this possibility (Isaacs et al., 1951; Munk et al., 1964; Galvin, 1965; Harris, 1967). Bowen suggested that the spacing of rip currents could be explained by an alongshore variation in breaker height induced by a standing edge wave. The conceptual link to nearshore morphology was provided by Bowen and Inman (1971), who noted that the drift velocity patterns above the bottom boundary layer due to a standing subharmonic edge wave were remarkably similar to commonly observed rhythmic nearshore features. Sediment suspension takes place in response to the incident wave stresses, but the edge waves provide the ordered perturbation that causes sediments to drift towards zones of convergence where they accumulate.

The model of Bown and Inman (1971) was extended by Holman and Bowen (1982) who generalized the standing edge wave hypothesis to include the interaction of two or more progressive edge waves of different mode. Drift velocities for different combinations of wave type (length, mode, direction, amplitude) were coupled to a sediment transport model in order to predict the resultant equilibrium topography. Crescentic bars were produced for the standing edge wave case, as predicted by Bowen and Inman (1971). Other combinations of modes produced well-documented topographical forms such as welded bars, meandering bars, and linear bars. For example, the interaction of two waves of the same frequency produced topography of three general types depending on the phase relationship and mode: only shore-parallel bars were produced if one mode was dominant, or the waves were not coherent; when the lower mode wave was of small amplitude or the two modes were partly coherent, rhythmic patterns were produced close to shore and linear bars were produced offshore; and totally rhythmic topography was produced by coherent waves of adjacent modal number. For the case of three or more modes, linear forms were produced if the phases were different. If the waves were coherent, complex topography was produced, although it was rhythmic at the scale of the longest wave mode in the interaction.

\section{Field and analysis techniques}

\section{Site and methods}

Field experiments were conducted in a nontidal nearshore zone, Wymbolwood Beach, 
Georgian Bay, Canada (Fig.1), during May and June of 1985 . The mean nearshore slope (below still water level) was approximately 0.0174 , and the sediments were well-sorted sand with a mean diameter of $0.21 \mathrm{~mm}$. The wave climate is storm-dominated and fetch-limited with a maximum fetch window to the west-northwest $(111 \mathrm{~km})$ and a maximum effective fetch from the west $(61 \mathrm{~km})$, and maximum significant wave heights at breaking of the order of $2 \mathrm{~m}$. A triple bar system comprising a linear and reasonably stationary outer bar, a quasistationary middle bar, and an irregular, crescentic inner bar, developed during the 1985 field experiments, immediately after the breakup of the nearshore ice pack in early April.

Hydrodynamic data were collected using electromagnetic flow meters and surface-piercing wave staffs which were cable-linked to a land-based, high-speed data acquisition and mass storage system (Greenwood and Sherman, 1983, 1984)., Model 512 biaxial flow meters

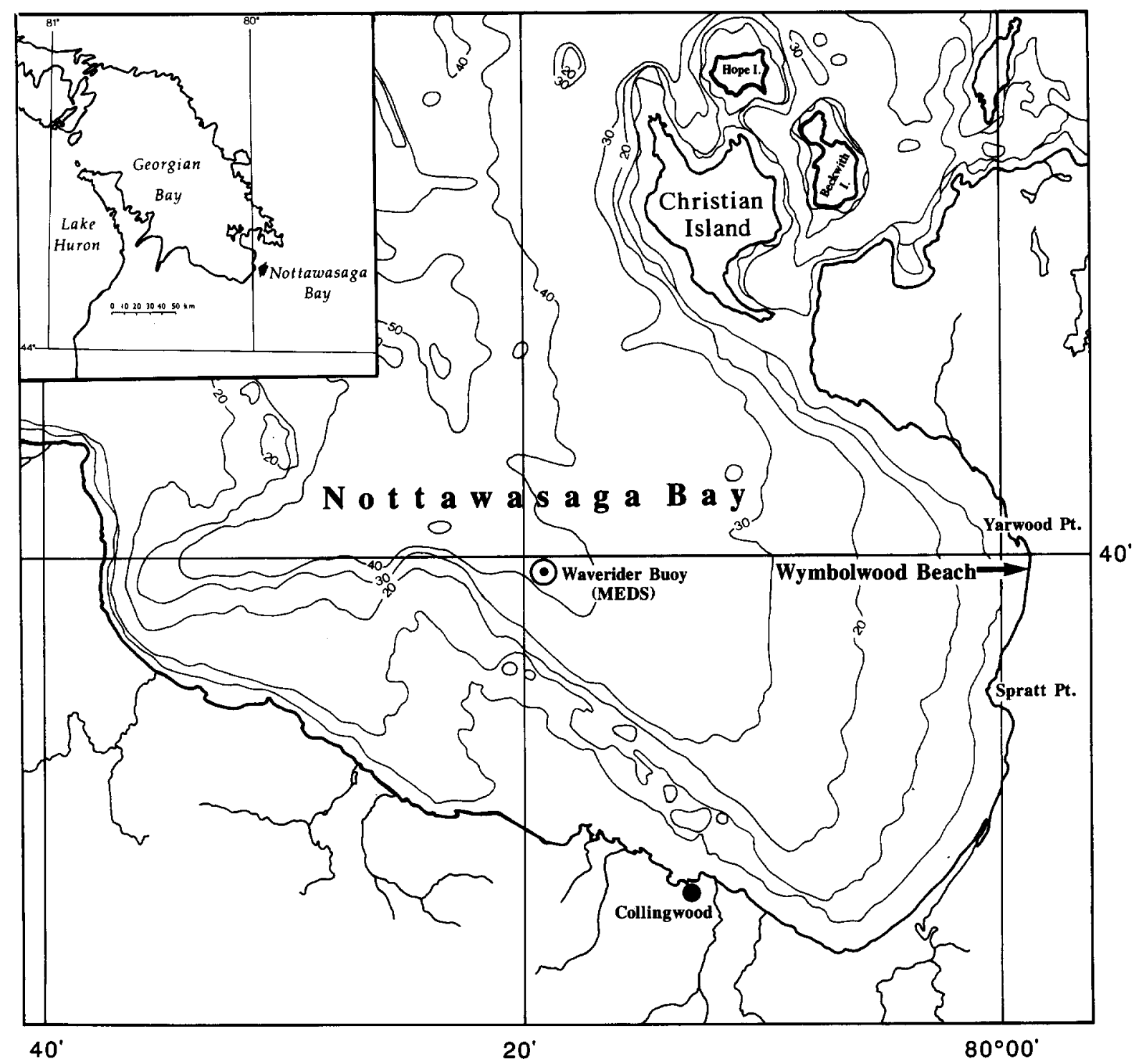

Fig.1. Location of experimental site. 
manufactured by Marsh-McBirney were deployed to measure horizontal currents. The characteristics of these current meters have been investigated extensively (Cushing, 1976; Kalvaitis, 1977; Cunningham et al., 1979) and thorough discussions of their accuracy and reliability are given by Huntley (1980b), Aubrey et al. (1984), Aubrey and Trowbridge (1985, 1988), Doering and Bowen (1987), Guza (1988), and Guza et al. (1988). The current meters used in this study were mounted on specially designed brackets and bases which were hydraulically jetted into the sand bed. The brackets facilitated adjustment in the three cardinal directions and the use of an orientation device ensured proper levelling and alignment to within plus or minus two degrees of the desired compass bearing.

Fluctuations in water surface elevation such as those associated with the passage of a wave or with set-up and set-down, were measured using continuous resistance wave staffs based on the design of Truxillo (1970). Each staff was mounted to a length of steel pipe by three PVC brackets and the whole assembly was jetted into the sand bed and guyed with steel cable, anchor, and turnbuckle rigging. Fluctuations in the water surface are manifest as DC voltage fluctuations which were digitized and sampled. Resolution of these instruments is of the order of $1 \mathrm{~cm}$ or less and they have proven to be effective and robust.

Net sediment volume and net morphological changes were assessed using standard profiling techniques (engineer's level, measuring tape, and stadia rod) across the subaerial beach and offshore to approximately the $2 \mathrm{~m}$ water depth, and then continued to greater offshore distances using a boat-mounted Raytheon DE719 Fathometer. In addition, depth-of-disturbance rods (DOD) consisting of 0.25 inch smooth steel rods and a loosely fitting washer were emplaced in dense grids so as to corroborate the survey data and to provide detailed information on sediment volume fluxes and depth of scour during storms. Grain-size samples were taken at periodic intervals during the course of a storm by SCUBA divers and from pre-storm and post-storm epoxy peels obtained by box coring in fulfillment of other aspects of this research effort. Further details of the instrumentation and methodology are given in Bauer (1988).

\section{Experimental design}

The field experiment was designed to investigate the three-dimensional nature of nearshore hydrodynamics and morphodynamics, with specific focus on the differentiation of wave type (incident versus edge; progressive versus standing; nodal structure). Figure 2 shows the instrument deployment configuration for the inner surf zone, and exact grid location codes are given in Table 1. During the 1985 experiments, up to eighteen wave staffs and fifteen electromagnetic current meters were installed along one shore-normal array and two shoreparallel arrays. Nine wave staffs in the shorenormal array (designated WW0 to WW08) were located at topographically significant locations (bar crest, bar face slope, trough) extending from the beach fact to $156 \mathrm{~m}$ offshore (approximately $3 \mathrm{~m}$ deep). Eight of the remaining staffs were located in two shore-parallel arrays (five staffs each); one in the inner trough at a distance of $15 \mathrm{~m}$ from the baseline (designated I1, WW01, I2, I3 and I4, from south to north), and an identical array in the middle trough at a distance of $45 \mathrm{~m}$ from the baseline (designated M1, WW03, M2, M3 and M4, from south to north).

Current meters were deployed alongside selected wave staffs as shown in Fig.2. Unfortunately, because of electronic problems and instrument burial or fouling, only two current meters were deemed reliable for the storm discussed in this paper (at positions WW01 and I3). The current meters were installed at an elevation of $0.20 \mathrm{~m}$ above the bed, as close to the top of the bottom boundary layer as possible without contravening the four probe diameter interference distance requirement (Aubrey et al., 1984). Subsequent bed elevation changes throughout the field season were monitored using the depth-of-disturbance rods, 


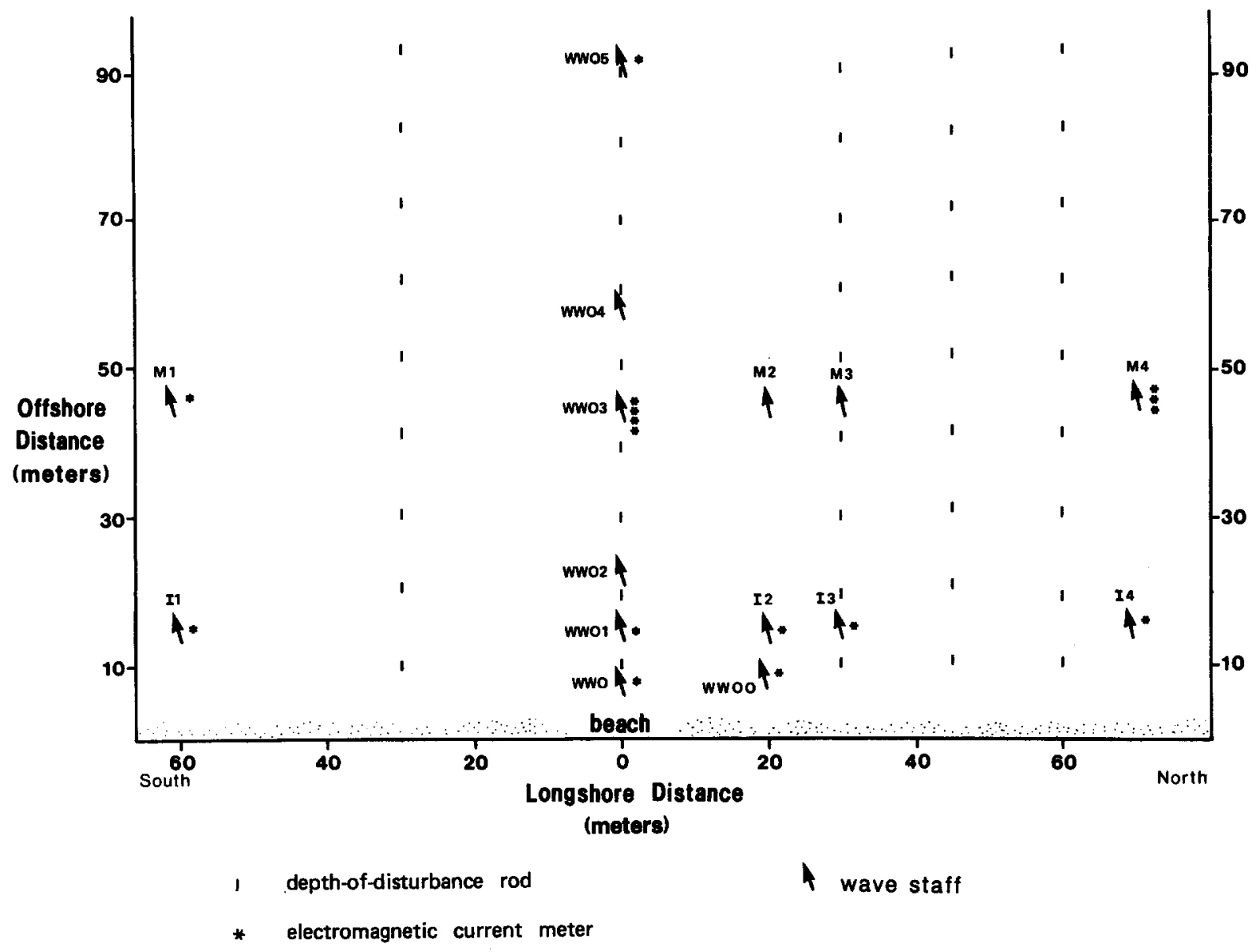

Fig.2. Instrument deployment configuration in the inner surf zone during the 1985 field experiments.

and sensor elevation adjustments made when possible. The current meters were located approximately $1 \mathrm{~m}$ to the north of their respective wave staffs; a distance which reflects a compromise between single point spatial sampling and minimizing electronic interference and flow distortion.

The sampling design reflects the need to record over a sufficiently long period so as to sample adequately the low-frequency motions without violating the stationarity requirements of the spectral procedures. Fortunately this was a non-tidal environment and shortterm water level changes were small (set-up and seiche effects notwithstanding). However, changes in the incident wave field can be rapid due to the passage of frontal systems and the accompanying shifts in wind speed and direc- tion. The speed and storage limitations of the data acquisition system yielded single data runs of $20 \mathrm{~min}$ in duration (2925 full scans of 40 channels at $0.41 \mathrm{sec}$ scanning interval). During storm events, runs were usually taken at $1 \mathrm{~h}$ intervals although the burst interval varied depending on the type of experiment and the nature of the storm.

\section{Data integrity}

Sensor raw voltages were converted to velocities or surface elevation fluctuations using empirical conversion constants specific to each instrument. Conversion constants for the current meters were derived from towing tank calibrations at the Canada Center for Inland Waters, Burlington, Ontario that in- 
TABLE 1

Wave staff locations

\begin{tabular}{llll}
\hline Staff & Grid & Staff & Grid \\
\hline WW08 & $(156,0)$ & I1 & $(15,60 \mathrm{~S})$ \\
WW07 & $(142,0)$ & I2 & $(15,20 \mathrm{~N})$ \\
WW06 & $(127,0)$ & I3 & $(15,30 \mathrm{~N})$ \\
WW05 & $(90,0)$ & I4 & $(15,70 \mathrm{~N})$ \\
WW04 & $(60,0)$ & M1 & $(45,60 \mathrm{~S})$ \\
WW03 & $(45,0)$ & M2 & $(\mathbf{4 5 , 2 0 \mathrm { N } )}$ \\
WW02 & $(26,0)$ & M3 & $(45,30 \mathrm{~N})$ \\
WW01 & $(15,0)$ & M4 & $(45,70 \mathrm{~N})$ \\
WW0 & $(7.5,0)$ & WW00 & $(7.5,20 \mathrm{~N})$ \\
\hline
\end{tabular}

Grid co-ordinates are: $X=$ offshore distance in meters from a permanent baseline on the subaerial beach; $Y=$ shoreparallel distance either north or south of the zero line (0).

volved towing at stepped velocities for each electrode pointing in the upstream direction. The calibrations were essentially linear throughout the range of velocities encountered in the field ( $R^{2}>0.99$ in almost all cases), and were unchanged since the previous testing (2-4 years prior to this field season). A great deal of faith can be ascribed to the reliability of these methods, and those instruments that were somehow problematic in the field were not considered in the final analysis.

Wave staffs were calibrated at the end of the field season using stepwise submersion tests. Although there were minor non-linearities at the lower parts of the staffs (as expected from theory), these calibrations were also remarkably linear ( $R^{2}>0.90$ in almost all cases). Second regressions were performed on revised data sets that excluded the bottom, non-linear parts and included only the operating range of the staff (upper 75\%). These improved calibration coefficients ( $R^{2}>0.95$ for most cases) were applied to the raw data.

Once the time series of converted current meter and wave staff data were calculated, a detailed validation procedure was applied to the records to test for stationarity and integrity. Extreme values which were considered to be physically impossible or which were outside the range of the instrument's capabilities were removed from the data sets and replaced by values from an interpolation sub-routine so as not to alter the time-dependency of the series. A small number of files which did not conform to the requirements of the subsequent analytical techniques were eliminated from further analysis. Spectral analysis was performed on the remaining files using the BMDPIT-1985 program (Dixon, 1985).

The morphological data derives from three sources: level surveys, depth-of-disturbance (DOD) measurements, and boat-mounted echo soundings. The survey data were reduced to a semi-permanent benchmark, and the offshore distance calculations were checked, whenever possible, with reference to fixed instruments within the surf zone (e.g., wave staffs or DOD rods which were accurately surveyed at the end of the field season). The elevation changes between subsequent surveys were then verified using the DOD measurements; the changes observed at every DOD location were cumulated and compared to the survey data for every storm. Differences between the two methodologies at the end of the field season were of the order of 1-2 cm, which is approximately the precision of the methods.

\section{Results}

\section{Spectral energy}

During the 1985 field season, several cyclonic disturbances passed over the site resulting in storms of varying magnitude. This paper is concerned with only one of these events (June 1-2) which was associated with the passage of a tornado directly to the south of the field site. Figure 3 shows the distribution of wave energy (total spectral variance) with time as measured by two wave staffs. WW07 characterizes the incidence conditions at $142 \mathrm{~m}$ from the baseline (not shown in Fig.2), whereas WW01 was closer to shore, only $15 \mathrm{~m}$ from the baseline. Maximum total spectral variance occurred at $0633 \mathrm{~h}$ on June 1 at both locations, and wind forcing of the wave field ceased by $1300 \mathrm{~h}$. Due to energy dissipation associated with bed friction and wave breaking, total 


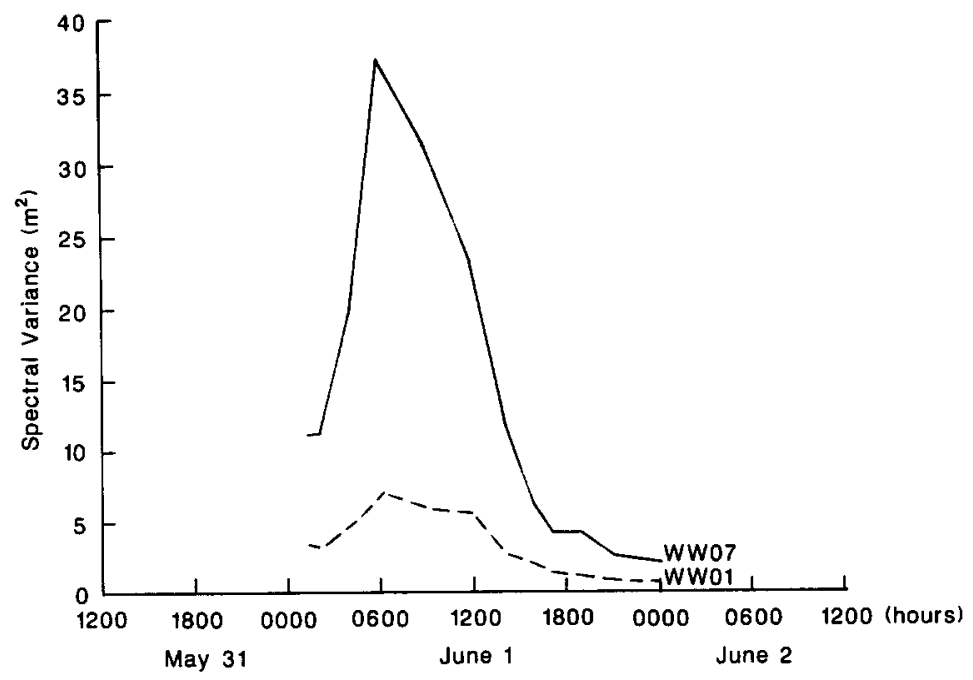

Fig.3. Total spectral variance for the June 1-2 storm as measured by two wave staffs: WW07 was in the outer part of the surf zone, WW01 was in the inner part of the surf zone.

spectral variance decreased substantially towards shore.

Figure 4 shows the spectral evolution of the wave field during the storm at three locations along the shore-normal wave staff array. WW03 was located $45 \mathrm{~m}$ from the baseline in the middle trough where waves were beginning to reform after having broken over the middle bar. WW0 was near the shoreline, only $7.5 \mathrm{~m}$ from the baseline (approximately $3 \mathrm{~m}$ lakeward of the average shoreline position). In general, the spectra from WW07 have a shape similar to conventional deep-water wave spectra with a fairly well-defined incident peak, a gradual slope along the high-frequency limb, but a rapid decline towards the lower frequencies. In the WW03 spectra, the incident peak is not as clearly defined and the high-frequency slope is much flatter. This may be due to the wave breaking and reformation processes cascading energy towards higher frequencies. In contrast, the lower frequency peaks at WW03 are fairly well defined and more energetic than at WW07. Closer to shore, at WW0, the spectral peaks are broad-banded, and it is difficult to identify the incident waves. Except for the rising limb of the storm, the lower frequencies dominate the spectra.

Despite the cross-shore trends, there are common features to all these spectra which characterize the evolution of the wave field as the storm progressed. A shift of the incident waves to longer period is evident towards the storm peak. The spectra at $0158 \mathrm{~h}$ show a peak centered around $0.210 \mathrm{~Hz}(4.8 \mathrm{~s})$, which shifts to $0.170 \mathrm{~Hz}(5.9 \mathrm{~s})$ at $0633 \mathrm{~h}$. In many marine environments, the incident peak tends to shift to higher frequencies as a storm passes. Holman et al. (1979) observed such a trend at their site and suggested that the dispersion of storm-generated waves caused the long-period, storm forerunners to arrive first. In contrast, the wave climate at Wymbolwood Beach is fetch-limited and strongly wind-forced, and therefore forerunners are generally absent. The spectral peak at $0.170 \mathrm{~Hz}(5.9 \mathrm{~s})$ remained fairly large until $1200 \mathrm{~h}$ despite slightly declining total spectral energies (Fig.4). By $1446 \mathrm{~h}$, total spectral energy had declined substantially, and the dominant spectral peak had shifted to higher frequency. Much of the incident energy at frequencies between 0.140 $\mathrm{Hz}$ and $0.200 \mathrm{~Hz}$, evident during the most energetic part of the storm, had been eliminated because of a veering in wind direction associated with the passage of the frontal system. A reversal in the direction of the longshore current also occurred at this time. 

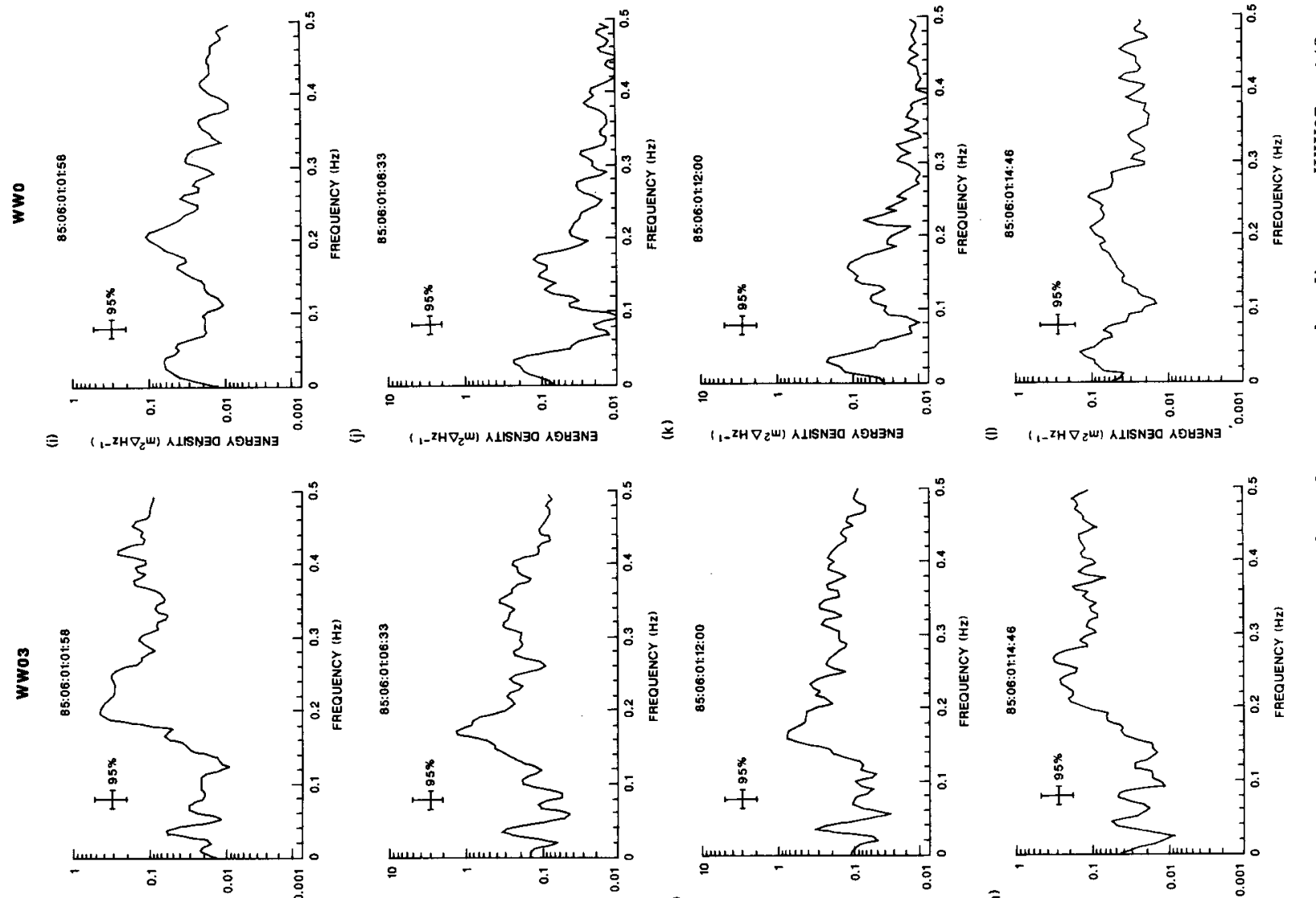

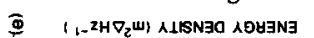

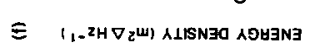

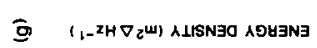

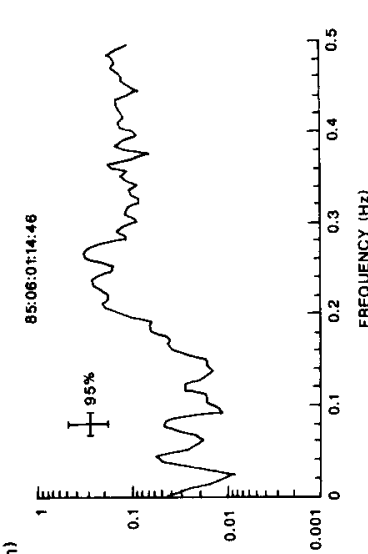

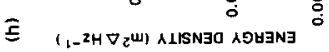

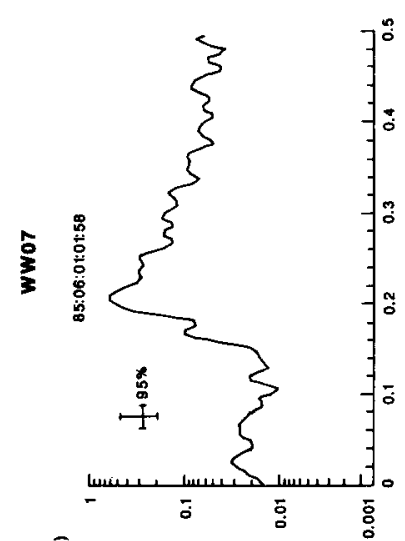

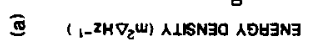

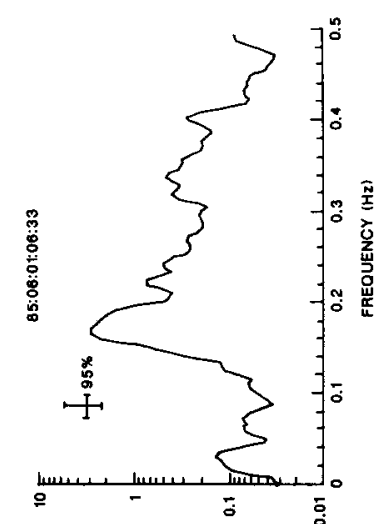

อิ $\quad\left(1-2 H \nabla_{2}\right.$ W) ALISNBO ADY3N3

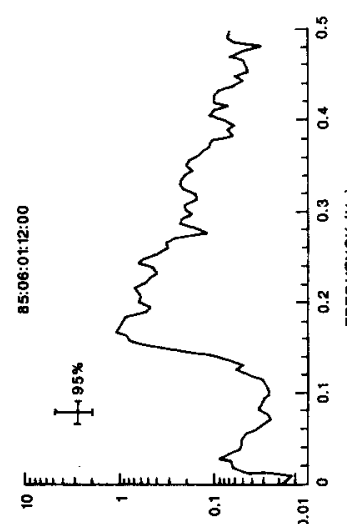

Ð

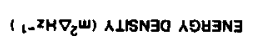

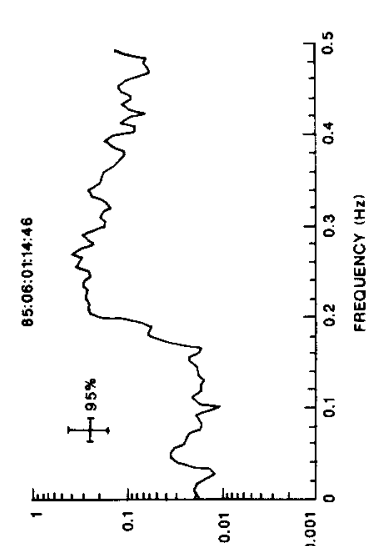

$\overline{\underline{ }}$

(1-ZHVZW) ALISN3O AOYYNA 
Another common feature of these spectra is a dominant low-frequency peak centered around $0.035 \mathrm{~Hz}(28.6 \mathrm{~s})$, especially for the inner surf zone at WW0 (Fig.4). It reached a maximum at $0633 \mathrm{~h}$ and then remained constant until $1200 \mathrm{~h}$ despite slightly declining incident wave energies. Thereafter, the energy in the $0.035 \mathrm{~Hz}$ peak decreased fairly rapidly with the decline in incident energy, although, unlike the incident energy peak which shifted in frequency, the low-frequency peak remained constant at $0.035 \mathrm{~Hz}$.

Figure 5 shows the temporal variation in low-frequency wave energy expressed as a percentage of total spectral variance in each spectrum (i.e., for every $20 \mathrm{~min}$ record throughout the storm). Note that the low-frequency energy was integrated between limits of 0.015 $\mathrm{Hz}$ and $0.145 \mathrm{~Hz}$ which are appropriate to the lacustrine system under investigation and do not correspond to those generally adopted for marine systems. Wave motions at frequencies less than $0.145 \mathrm{~Hz}$ have periods greater than those expected for incident gravity waves at this beach, and wave motions at frequencies less than $0.015 \mathrm{~Hz}$ can not be resolved given the short record length. Any variability evident in Fig. 5 is due solely to changes in the shape of the spectrum (i.e., a different energy distribution across frequency space). These normalized curves no longer give any indication of the total spectral energy distribution of the storm, as did Fig.3.
At the outer surf zone location (WW07), only a small proportion (less than $20 \%$ ) of total spectral variance occurred in the low-frequency band. Closer to shore, this percentage increased markedly: $41 \%$ at WW01 and 57\% at the beach face. The percent energy in the lowfrequency band increased rapidly at about the same time as the maximum total spectral wave energies. Similar observations of the increasing relative importance of the lower frequency motions during storms have been made by many others (e.g., Holman et al., 1979; Huntley, 1980a; Holman and Bowen, 1984; Oltman-Shay and Guza, 1987). However, in the present case, maxima in the low-frequency bands did not occur until about $3 \mathrm{~h}$ after the peak in total spectral variance (Fig.5). During these three hours, total spectral variance actually decreased. Such lags are suggestive of a resonance mechanism by which energy can be cascaded to low-frequency motions despite declining incident energy inputs.

\section{Edge wave signatures}

\section{Phase and coherence spectra}

In order to establish a link between nearshore hydrodynamics and morphodynamics, it is necessary to identify structure in the lowfrequency motion. One operational approach to separating various modes of wave motion is to compare the observed motion at a particular frequency with theory (e.g., Huntley et al.,

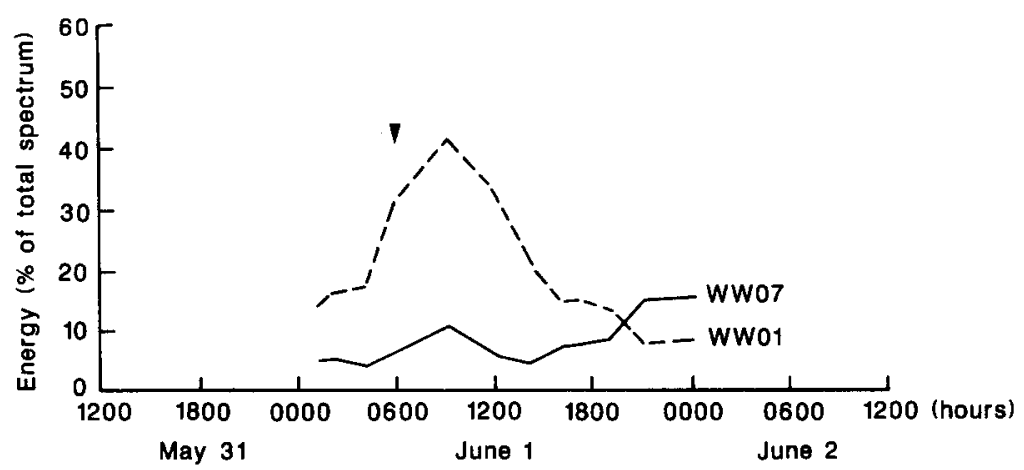

Fig.5. Percent of total spectral variance for the June 1-2 storm in the low-frequency part of the wave spectrum (0.015 $\mathrm{Hz}$ to $0.145 \mathrm{~Hz}$ ). Note the time lag between the peak of the storm based on total spectral variance (indicated by the vertical marker) and the low-frequency peaks. 
1981; Huntley and Kim, 1984; Kim and Huntley, 1986). Figure 6 shows three energy spectra taken from contemporaneous time series from a colocated current meter and wave staff pair
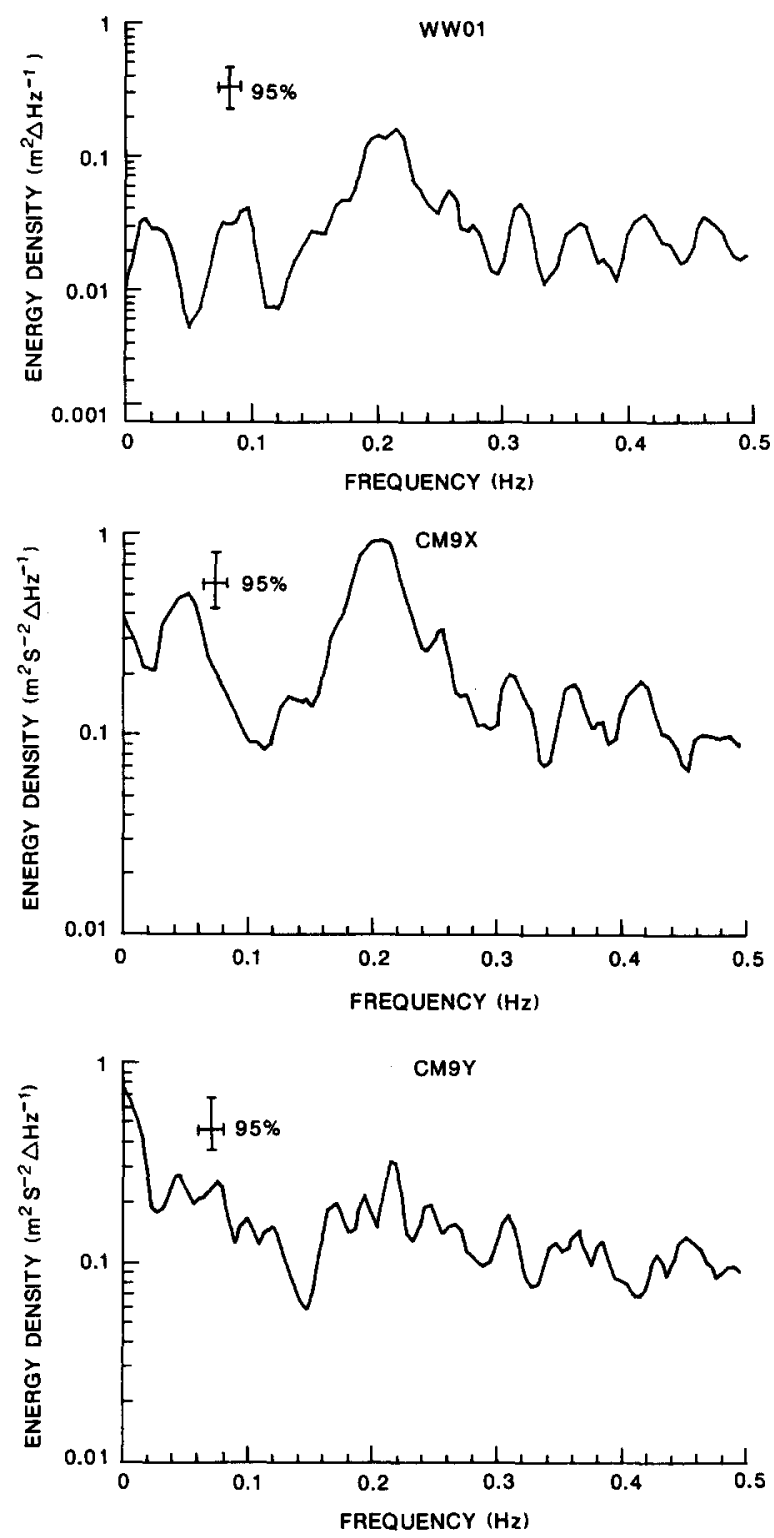

Fig.6. Wave energy spectra from a colocated wave staff-current meter instrument pair at $0158 \mathrm{~h}$ on June 1 . WW01 refers to the wave staff. CM9X refers to cross-shore velocity measurements, and CM9Y refers to shore-parallel velocity measurements. Note the different energy density scales. at WW01, close to shore, during the June 1-2 storm. The other current meter and wave staff pair at I3 gave essentially the same results, and therefore, they are not reproduced here. An incident energy peak centered at $0.210 \mathrm{~Hz}$ is readily apparent in the $\eta$ and $\boldsymbol{u}$ spectra, but is not as obvious in the $v$ spectrum. The low frequency peaks are inconsistent, and it is difficult to identify wave structure from these spectra alone. However, the phase and coherence information derived from these spectra is useful in establishing structure in the wave motions. Standing edge waves at a specific frequency, for example, can be identified on the basis of a unique set of phase relationships between the cardinal velocity vectors (although this is not necessarily true of all wave modes). The phase angles between the horizontal velocity vectors $u$ - cross-shore; $\mathbf{v}-$ alongshore) and surface elevation fluctuations $(\eta)$ for a standing edge wave should be as follows,

$\frac{u-\eta}{\text { quadrature }} \quad \frac{\boldsymbol{v}-\eta}{\text { quadrature }}$ in $\frac{\boldsymbol{u}-\boldsymbol{v}}{\text { phase }}$

where "quadrature" implies a phase angle of $90^{\circ}$ or $270^{\circ}$, and "in phase" implies a phase angle of $0^{\circ}, 180^{\circ}$, or $360^{\circ}$.

The phase and coherency spectra derived from the energy spectra in Fig. 6 are presented in Fig.7. A 95\% confidence level was calculated for the coherence-squared statistic following the methodology of Thompson (1979) and Julian (1975). In the frequency range greater than $0.150 \mathrm{~Hz}$, almost all the motions are in phase, indicating the presence of progressive gravity waves. This was especially evident for the incident wave band centered around 0.210 $\mathrm{Hz}$. The general decline in coherence at higher frequencies may be associated with the small spatial separation of the wave staff and current meter. However, since the steady shift in phase was small, the effect appears to be minimal. A similar phase shift would not be evident at lower frequencies because of the large length scales of the waves relative to instrument separation. The electronic filtering characteristics of the Marsh-McBirney flow meters may 

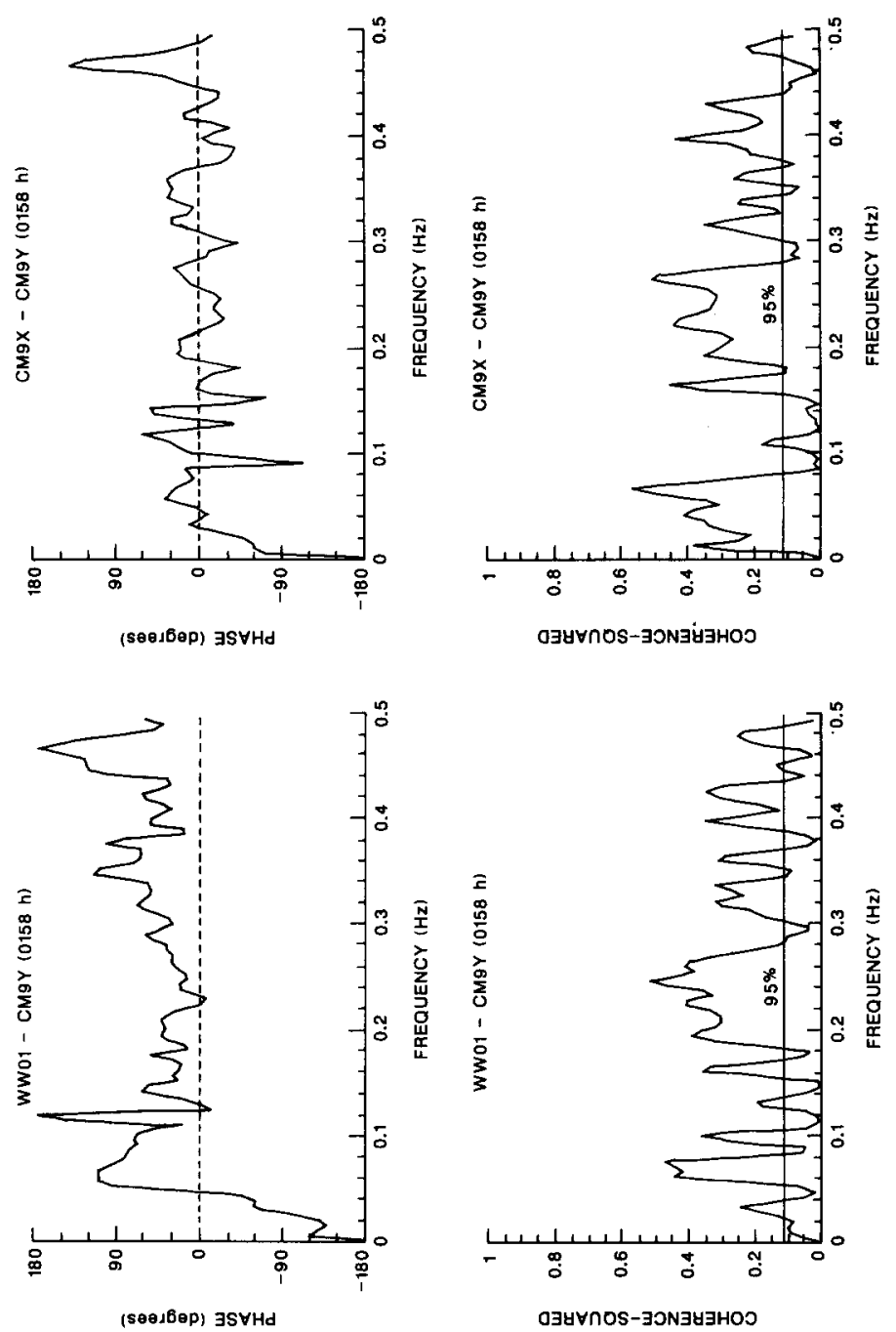

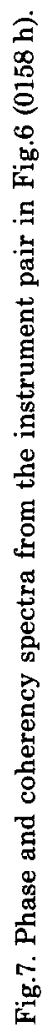


account for part of the phase shift between the wave staff and current meter at high frequencies, but this effect is most pronounced at frequencies greater than $0.3 \mathrm{~Hz}$ (Guza, 1988; Doering, pers. commun.). In the low-frequency parts of the phase and coherence spectra there is some evidence in support of the presence of edge wave motion. At frequencies of $0.035 \mathrm{~Hz}$ and $0.07 \mathrm{~Hz}$, for example, the phases in Fig.7 are consistent with standing edge wave motion, and the associated coherences are statistically significant.

Figure 8 shows the phase relationships taken from the colocated current meter and wave staff pair at WW01 for the motions centered around $0.035 \mathrm{~Hz}$ at various times throughout the storm. There is excellent correspondence with the theoretical phases for a standing edge wave. Occasionally, there are deviations from the expected phase, but these cases tend to have smaller coherence, which may indicate the presence of additional modes of motion near that frequency. Since statistically stable estimates of spectral energy are obtained by averaging periodograms over many adjacent band widths, a certain amount of smearing of even the purest signal is to be expected. Towards the latter part of the storm, the phase estimates became less significant (smaller coherence-squared) due to a declining signal-tonoise ratio associated with a reduction in the forcing and increased turbulence due to wave breaking close to shore. The phases at other low frequencies were not as consistent, nor were the energy levels as high. Attention was directed therefore toward the $0.035 \mathrm{~Hz}$ motion that was conspicuous in the low-frequency parts of the energy spectra in Fig.4.

\section{Cross-shore structure}

Edge waves have a very specific offshore structure that depends on the Laguerre polynomial function (eq.2). Wave staffs deployed at nodal positions of an edge wave (or standing wave) at a specific frequency would not measure any motion due to that wave, despite its presence. For every offshore position, then, there are a series of frequencies at which a node in the wave motion would be encountered, and these would appear as energy

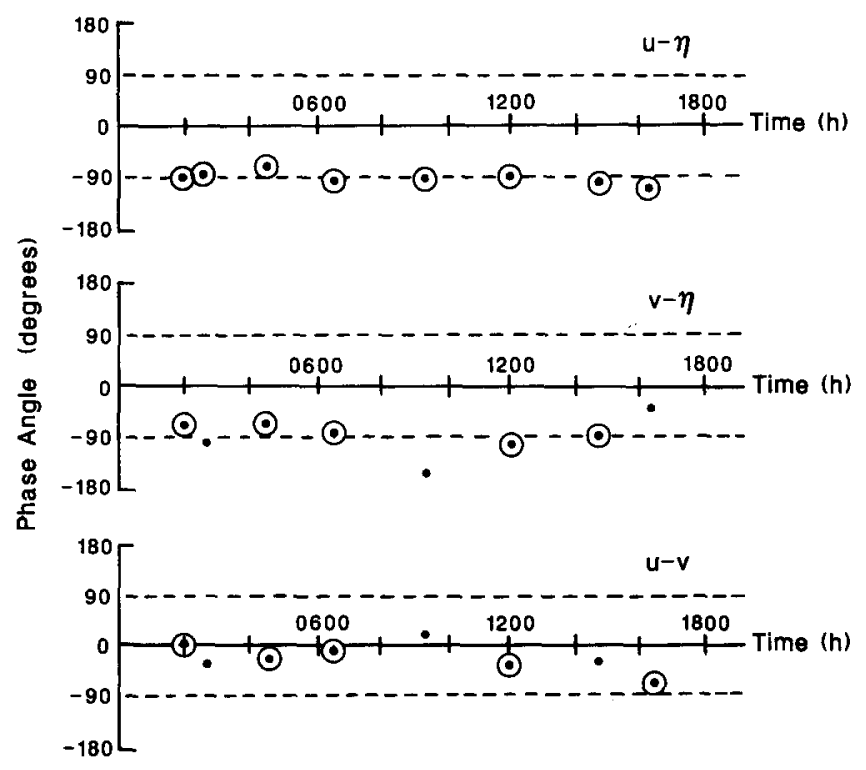

Ocircled points indicate significance at $5 \%$

Fig.8. Phase relationships of the $0.035 \mathrm{~Hz}$ fluid motions in the three cardinal directions as measured by a colocated wave staff and current meter pair at position WW01 on June 1 . The phases correspond closely to those of a standing edge wave (quadrature, quadrature, in phase). 
troughs in the frequency spectrum of surface elevation. Maximum signals would be measured at antinodal points only, and at intermediate locations, only a fraction of the maximum signal would be evident. Because of this, interpretation of low-frequency spectral energy peaks can become problematic unless synthetic spectra can be generated as comparisons (e.g., Sallenger and Holman, 1985, 1987). Progressive gravity wave motion is not subject to such constraints.

One approach to resolving the cross-shore structure of wave motion at a given frequency is to plot the variance at that frequency at numerous offshore locations, and compare the trends to the cross-shore structure of known wave modes. Figure 9 is such a variance plot of the $0.035 \mathrm{~Hz}$ motion from the cross-shore array of wave staffs plotted according to non-dimensional offshore distance. Also plotted are the non-dimensional velocity potentials for two theoretical wave modes: a standing wave and a mode 3 edge wave. For purposes of visual comparison, the measured variances from wave staffs with similar gain characteristics were normalized uniformly so that non-dimensional variance of at least one of the wave staffs equaled that of a theoretical profile. Although other normalization procedures could have been used, the main purpose of this plot is to indicate the complex offshore struc- ture of the $0.035 \mathrm{~Hz}$ motion. Maximum variance was always measured closest to shore, as expected for edge wave motion in general. However, the decay in energy with offshore distance was not simple, as with lower mode edge waves, since the outermost wave staff at a non-dimensional distance of approximately 41 consistently measured stronger motions than some of the inner wave staffs. It is clear that lower mode edge wave profiles do not explain the data well because the theoretical offshore decay of energy with these modes is too rapid. A mode 2 edge wave, for example, has less than $10 \%$ energy remaining at a non-dimensional distance of approximately 30 . The fit to the standing incident wave and mode 3 edge wave profiles, however, is quite reasonable. Furthermore, the phase relationships discussed in the previous section demonstrated that the motion was consistent with an edge wave standing in the alongshore direction, but not with an incident gravity wave standing in the crossshore direction. Therefore, the data presented thus far suggest that the wave motion centered around $0.035 \mathrm{~Hz}$ can be explained, in large part, by the presence of a standing edge wave of mode 3 or greater.

\section{Spatially lagged cross-spectra}

Cross-spectral analysis of time series from pairs of instruments along the shore-parallel

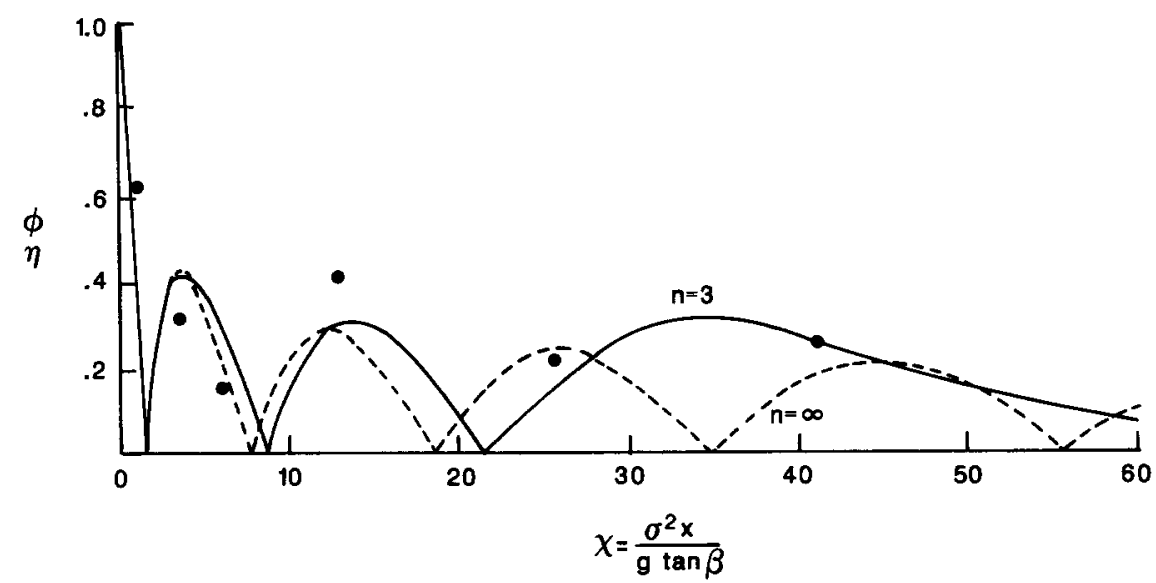

Fig.9. Offshore structure of the $0.035 \mathrm{~Hz}$ motion as measured by the shore-normal wave staff array. Dots indicate the spectral energy density $\left(\mathrm{m}^{2} \Delta \mathrm{Hz}^{-1}\right)$ adjusted linearly to provide the best fit with the theoretical profiles. 
wave staff arrays can yield considerable insight into the alongshore structure of wave motion at specific frequencies, and can be used to substantiate the hypothesis that the 0.035 $\mathrm{Hz}$ motion was standing in the shore-parallel direction. The phase information from these spatially lagged cross-spectra gives an indication of the presence and location of nodes and antinodes in the shore-parallel direction, and therefore, the alongshore wavelength. An incident wave that is standing in the shore-normal direction, for example, would produce "in phase" relationships across all instrument pairs of the alongshore array.

The two shore-parallel arrays of wave staffs, deployed at distances of 15 and $45 \mathrm{~m}$ from the baseline (Fig.2), were designed to give coarray spacings of $10,20,30,40,50,60,70,80,90$, and $130 \mathrm{~m}$. Figure 10 is a plot of phase angles of the motions from the inner wave staff array at a frequency of $0.035 \mathrm{~Hz}$ towards the latter part of the June 1-2 storm. Many similar plots were produced for different frequencies which demonstrated significant coherence, but most of these did not reveal the presence of alongshore structure. However, at a frequency of $0.035 \mathrm{~Hz}$, there was an "in phase" relationship of $0^{\circ}$ between the surface elevation fluctuations at pairs of wave staffs that were spaced less than approximately $55 \mathrm{~m}$, and an "in phase" relationship of $180^{\circ}$ between the surface elevation fluctuations at pairs of wave staffs that were spaced greater than approximately $75 \mathrm{~m}$ (up to $130 \mathrm{~m}$, the maximum extent of the coarray). In addition, all of the $180^{\circ}$ phase angles involved the southernmost wave staff (I1), and all of the $0^{\circ}$ phase angles involved the wave staffs north of and including WW01. The only instrument pairs which did not show statistically signifcant coherence were those at separation distances of 60 and $70 \mathrm{~m}$.

The phase angles presented in Fig.10 are interpreted as being due to a shore-parallel standing wave form with an alongshore wavelength of approximately $150 \mathrm{~m}$, slightly longer than the array of instruments. Nodes in surface elevation fluctuation appear to the south of I1, to the south of WW01, and to the north of I4. Such a nodal structure explains the $0^{\circ}$ phase angles between instrument pairs spaced less than $55 \mathrm{~m}$ because the wave staffs at WW01, I2, I3, and I 4 would have been encompassed by one-half of the standing wave (i.e., they all fall between adjacent nodes). Since both WW01 and I4 were located close to nodal points, and since the standing form is not expected to be perfectly fixed in space, the coherence between these two staffs should not be large, as

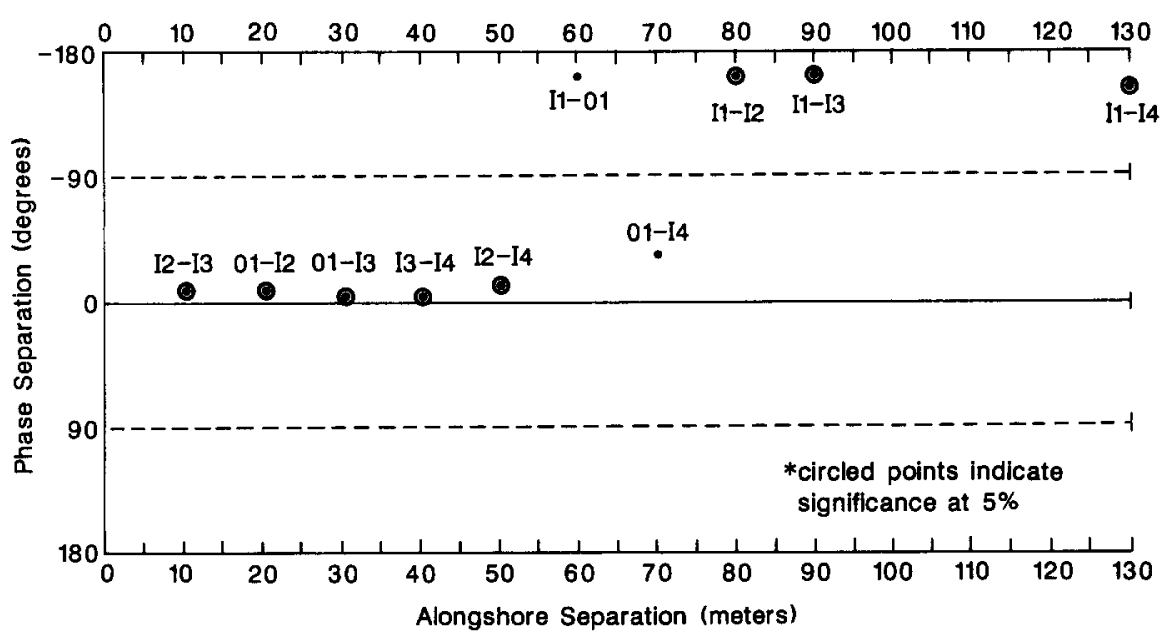

Fig.10. Phase angles for the $0.035 \mathrm{~Hz}$ motion between pairs of wave staffs along the inner, shore-parallel instrument array. Relative position of the staffs from south to north was $11,01, \mathrm{I} 2$, I3, and I4; 01 refers to WW01, which also lies along the crossshore instrument array. The time was $1446 \mathrm{~h}$ on June 1. 
observed (note however, that the phase angle is still close to $0^{\circ}$ ). Similarly, a nodal point immediately to the south of WW01 explains the $180^{\circ}$ phase angle between I1 and the other wave staffs along the instrument array, and also the lack of a statistically significant coherence on the $180^{\circ}$ phase angle between I1 and WW01.

\section{Length scales of the edge wave}

The length scales of an edge wave of specific mode and frequency can be calculated using the analytical solutions presented earlier (eqns.1-3). It should be noted, however, that these solutions were derived assuming a plane beach. Analytical solutions also exist for more complex geometries, but they do not exist for barred profiles. Only numerical solutions to the governing equations are available for barred profiles (e.g., Holman and Bowen, 1979; Kirby et al., 1981). These numerical models suggest that the presence of bar crests can cause the antinodes of surface elevation to be modulated in amplitude and shifted in location. However, the numerical modelling of Kirby et al. (1981) also demonstrates that the dispersion relationship for the plane beach solutions is not altered by the presence of a barred profile. Thus, the alongshore length scales and the location of alongshore nodes calculated using the analytical or numerical solutions are identical. A significant shortcoming inherent to both approaches is that it is not known how edge wave forcing responds to complex, three-dimensional topography, nor how phenomena such as wave set-up should be incorporated into the solutions. It appears that edge waves are forced over distances much greater than the usual experimental site, and that they respond fundamentally to some mean beach slope averaged over the offshore extent of the edge wave profile (e.g., Huntley et al., 1981). Thus, for this study and as a first approximation, it was thought prudent to take the least-subjective approach to calculating the edge wave length scales based on a linear slope, rather than engage in a best-fit, numerical, curve-fitting exercise. Figure 11 shows a typical offshore profile during the experimental period and the least-squares regression line at a vertical exaggeration of five times. It is clear that the deviations from a linear slope are not extreme. Indeed, the correlation coefficient for the regression was of the order of 0.9 for almost all profiles during this storm. The linear regression slopes from approximately fourteen offshore profiles across the experimental site before and after the storm were averaged, and this value was used in the plane beach equations.

The cross-shore variance plot in Fig.9 indicated that the offshore structure of the 0.035

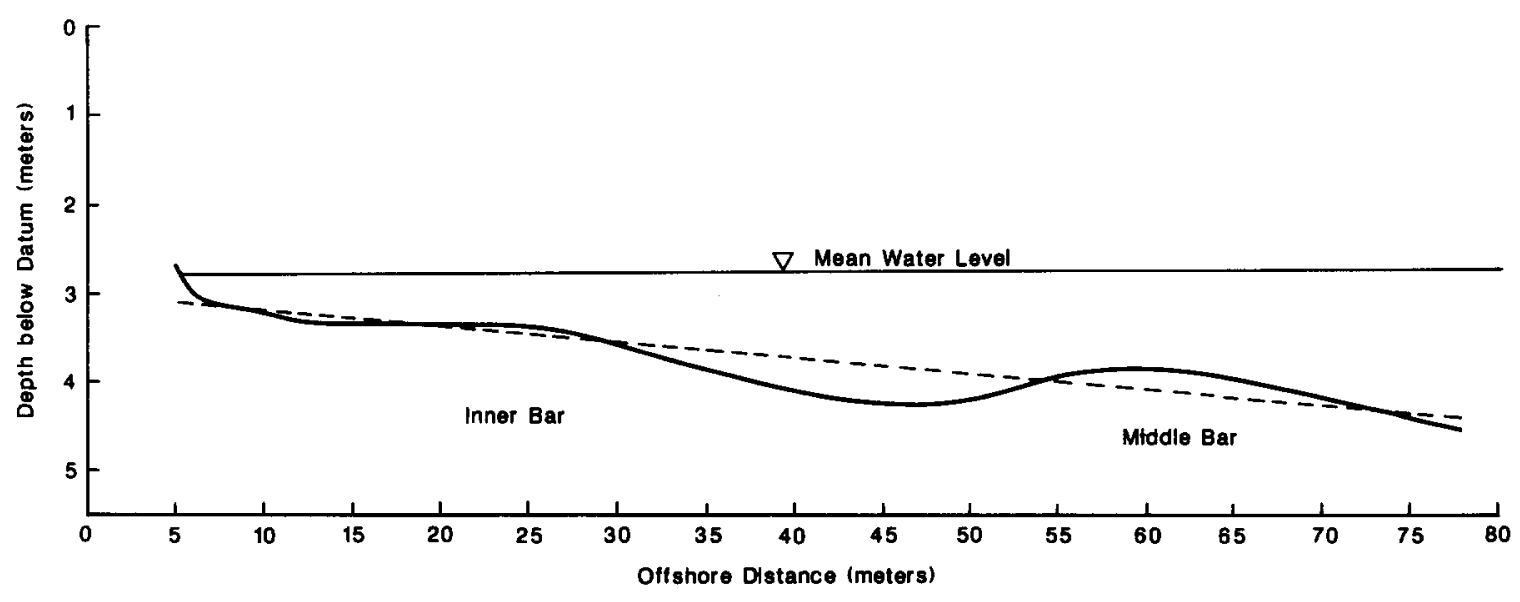

Fig.11. Nearshore profile along the Zero line, May 28, 1985. The straight line is the least-squares regression line for the profile data with a slope of 0.0178 and a correlation coefficient of 0.91 . Vertical exaggeration is 5 times. 
$\mathrm{Hz}$ motion was complex, and likely due to a mode 3 or greater edge wave. The phase plot in Fig.10 indicated that this motion was standing in the alongshore direction with a wavelength of approximately $150 \mathrm{~m}$. The critical issue then, is whether these empirical length scales are consistent with theoretical expectation. Assuming that the motion was due to the simplest possible edge wave, of mode 3 , and adopting an average nearshore slope of $0.0165\left(0.945^{\circ}\right)$ for the June 1-2 storm, the dispersion relationship (eqn.3) yields an alongshore wavelength of $147 \mathrm{~m}$. This value is in remarkable agreement with the one deduced from the spatially lagged cross-spectral plot in Fig.10. Lower mode waves would be considerably shorter ( $L=105 \mathrm{~m}$ for mode 2 ), whereas the higher mode waves would be much longer $(L=188$ for mode 4). This lends some credence to the assumption that the mode 3 wave contributed substantially to the motion at this frequency during this storm.

Figure 12 shows the expected nodal and antinodal lines in surface elevation fluctuations for a $0.035 \mathrm{~Hz}$, mode 3 , standing edge wave. Nodes in the offshore direction occur at $9.4 \mathrm{~m}, 31.4 \mathrm{~m}$, and $78.0 \mathrm{~m}$ from the baseline (average shoreline was displaced $4.5 \mathrm{~m}$ from the baseline for this storm). The positions of antinodes were calculated by taking the first derivative of eq.(2) and setting the resultant equal to zero. The roots were solved by iteration and substituted in the following expression for non-dimensional offshore distance,

$\chi=\frac{\sigma^{2} x}{g \tan \beta}$

to yield antinodes at $17.0 \mathrm{~m}, 50.2 \mathrm{~m}$, and $122.3 \mathrm{~m}$ from the baseline.

The specific locations of nodes and antinodes in the shore-parallel direction were determined from the phase separations presented in Fig.10 which suggested the presence of a nodal line just to the south of the shore-normal instrument array. The actual location of this nodal

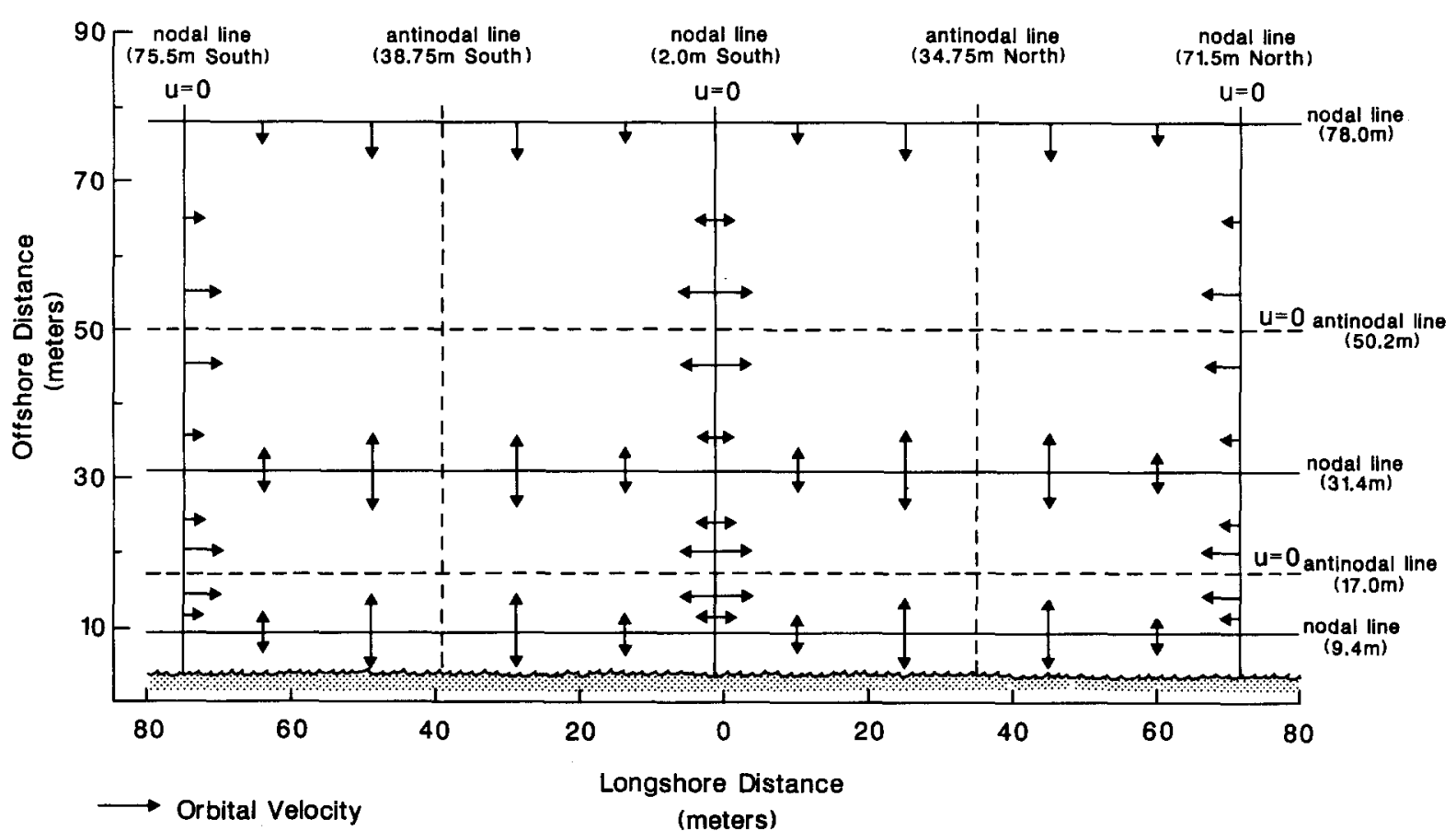

Fig.12. Scheme of the nodal structure, nodal position, and orbital velocity vectors associated with a mode 3 standing edge wave at $0.035 \mathrm{~Hz}$. The length scales were calculated using a mean beach slope of 0.0165 and the alongshore position of the nodes was fixed on the basis of Fig.10. 
line was placed $2 \mathrm{~m}$ towards the south, and therefore subsequent nodal lines appear at $75.5 \mathrm{~m}$ south and $71.5 \mathrm{~m}$ north of the instrument array. Since the alongshore behavior of edge waves is sinusoidal (eqn.1), antinodes in surface elevation appear at $38.75 \mathrm{~m}$ south and $34.75 \mathrm{~m}$ north of the instrument array, also consistent with the measured phase separations presented in Fig.10.

\section{Forcing of the edge wave}

Speculation on the forcing of the standing edge wave centered at $0.035 \mathrm{~Hz}(28.6 \mathrm{~s})$ derives from two observations apparent in the spectra of Fig.4. First, this low-frequency energy increased with the incident energy towards the peak of the storm, and then, was sustained for a subsequent period of almost $6 \mathrm{~h}$, despite the general decline of the incident waves. Second, the frequency of the standing edge wave remained constant at about $0.035 \mathrm{~Hz}(28.6 \mathrm{~s})$ even though there was a shift in the incident wave peak from approximately $0.210 \mathrm{~Hz}(4.8 \mathrm{~s})$ to $0.170 \mathrm{~Hz}(5.9 \mathrm{~s})$. Other researchers have ascribed such constancy of the low-frequency motion, despite changing incident wave conditions, to selective alongshore topographic trapping of specific wave modes (e.g., Holman et al., 1979; Huntley et al., 1981; Culley and Holman, 1985). There are no submarine canyons at the Wymbolwood site, although there is a pronounced curvature to the shoreline a few miles to the north of the site which may play a role in nearshore resonances. Huntley (1980a) and Wright et al. (1986) suggested that even if alongshore controls are absent the low-frequency wave field may actually "tune" itself in the presence of a barred topography. The theory of Kirby et al. (1981) and of Symonds and Bowen (1984) reinforces the possibility of such resonances, and such trapping may account for the variance amplification evident at certain offshore locations in Fig.9.

An alternative explanation involves the resonant forcing of the standing edge wave by the incident wave motion alone. Under this hypothesis the complexities associated with wave-topography interactions (Guza and Inman, 1975) or with viscous and turbulent damping (Guza and Bowen, 1977; Bowen and Guza, 1978) are ignored for the moment. Rather, it is necessary to demonstrate correspondence between a forcing function that is characteristic of the incident wave field, and the growth and decay of the low-frequency energy. For example, a number of studies have shown a correlation between the growth of infragravity energy and the growth of the envelope of specific band-passed parts of the incident wave field (e.g., Huntley and Kim, 1984; Guza and Thornton, 1985; Middleton et al., 1987).

In order to determine if a relationship between the incident energy and the lowfrequency motion existed, the wave motions at WW07 and WWO were examined in detail. Figure 13 shows the growth of the variance in the low-frequency band at WWO as a function of the growth of the high-frequency band at WW07. The rationale for such a plot is that edge wave energy should be most evident closest to the shoreline, and this energy may be forced by some function of the incident wave field. A one-to-one correspondence would imply that an increase or decrease in the incident wave energy causes a proportional response in the low-frequency motion, as might be the case for forced wave modes (due to radiation stress, for example). Free wave modes are resonantly forced and should demonstrate temporally lagged response due to inertial effects. The diagram shows that after an initial growth period, the high-frequency energy reached a maximum fairly rapidly $(0425 \mathrm{~h})$ and this was maintained for almost five hours $(0922 \mathrm{~h})$. During this period of constant high-frequency energy, the low-frequency energy increased continuously to a maximum at $0922 \mathrm{~h}$. The subsequent decrease in both low- and highfrequency energy corresponds closely to a oneto-one relationship although the decrease in low-frequency energy was slightly more pronounced, at least initially, than the decrease in high-frequency energy.

The trends in Fig.13 suggest that there was a temporal lag between an increase in the high- 


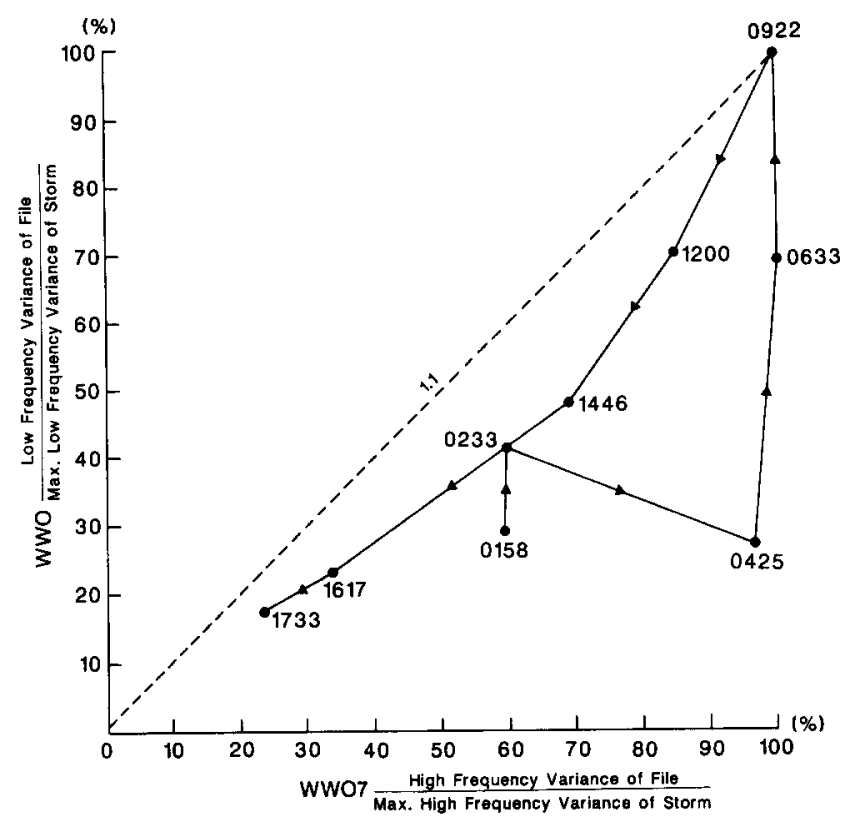

Fig.13. Relationship between the low-frequency motion close to shore and the high-frequency motion in the outer surf zone during the June 1-2 storm. A lag in the response of the low-frequency motion is indicated during the early part of the storm by the lack of correspondence to the 1:1 line. The high-frequency energy was at a maximum at $0633 \mathrm{~h}$, whereas the lowfrequency energy did not reach a maximum until $0922 \mathrm{~h}$.

frequency forcing and the subsequent growth of the low-frequency energy. In fact, it appears that the high-frequency motion continued to transfer energy to lower frequencies and caused growth, even though the total energy in the high-frequency motion did not increase. Since edge waves are free modes but are trapped to the shoreline, such energy transfers are not unexpected and indeed, resonance theory predicts such growth. However, accepting such temporal lags in the response to forcing, it is surprising to observe the rapid decline in low-frequency energy shortly after $0922 \mathrm{~h}$ when the high-frequency energy began to decrease. One would expect free modes of low-frequency motion to persist for some time after the decline of the high-frequency energy unless destructive modes become important.

In order to investigate the forcing further, the dominant frequency bands were isolated to determine if specific resonances existed, as predicted by theory. The low-frequency motion at $0.035 \mathrm{~Hz}(28.6 \mathrm{~s})$ and the incident peak at the beginning of the storm centered at $0.210 \mathrm{~Hz}$
$(4.8 \mathrm{~s})$ were of particular interest. The theory presented by Bowen and Guza (1978) on the resonant forcing of edge waves by surf beat requires three waves to satisfy the triad resonance conditions (eqn.4): the frequency of the edge wave equals the difference frequency of the two incident waves. If the 0.035 and 0.210 $\mathrm{Hz}$ motions represent two waves of a resonant triad, then the third wave must have a frequency of approximately $0.175 \mathrm{~Hz}(5.7 \mathrm{~s})$. It is intriguing to note that during the most energetic periods of this storm, a large proportion of the incident wave energy appeared in a frequency band centered at $0.175 \mathrm{~Hz}$ (Fig.4).

Figure 14 shows the energy growth and decay in the $0.035,0.175,0.210$, and combined $0.175+0.210 \mathrm{~Hz}$ bands at WW03. The intermediate surf zone location at WW03 was chosen since a substantial proportion of the incident wave energy was dissipated across the inner surf zone, and very little incident wave energy was evident close to shore (WW0). A marked increase in the low-frequency energy was apparent between 0425 and $0633 \mathrm{~h}$, and an 


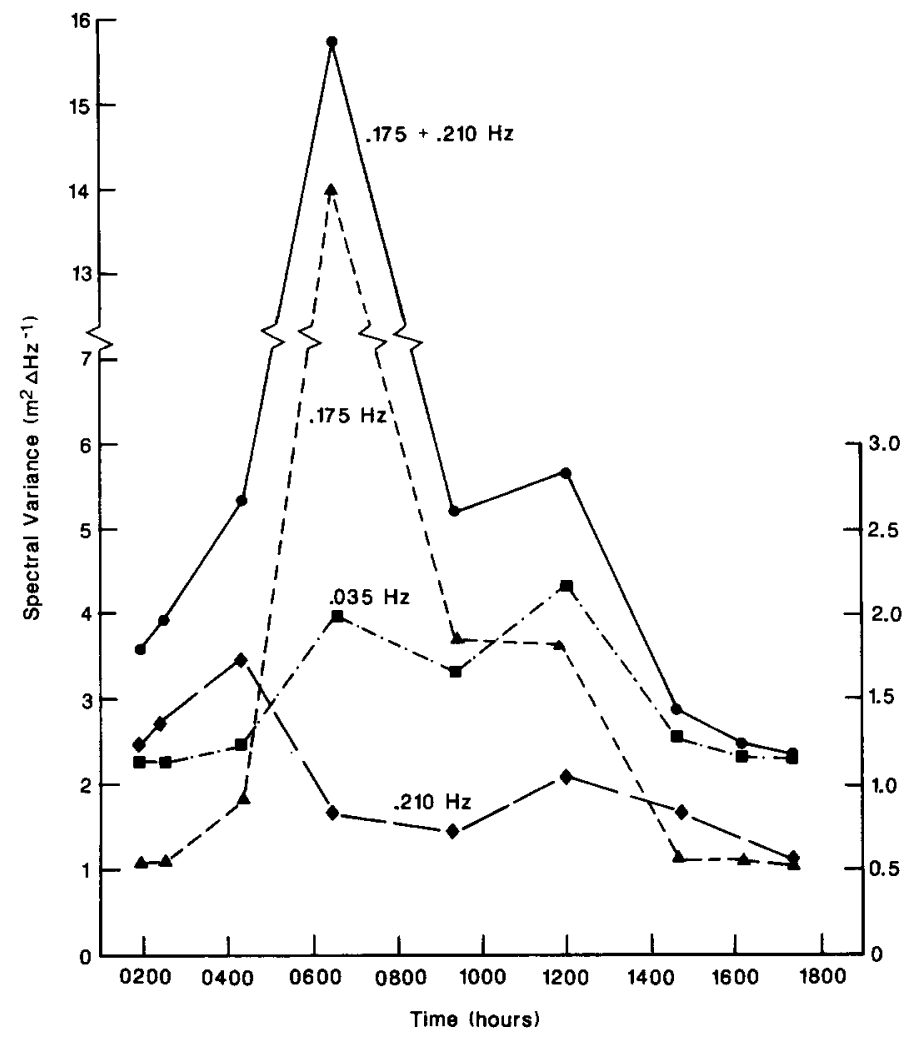

Fig.14. A hypothetical triad resonance showing the growth and decay of the $0.035 \mathrm{~Hz}$ standing edge wave energy as a function of the interaction of two incident waves at $0.175 \mathrm{~Hz}$ and $0.210 \mathrm{~Hz}$. The measurements were taken at WW03. The axis on the right refers to the $0.035 \mathrm{~Hz}$ spectral variance only.

overall decline occurred after $1200 \mathrm{~h}$. The trends in the 0.175 and $0.210 \mathrm{~Hz}$ bands individually do not follow those in the $0.035 \mathrm{~Hz}$ band particularly well. Between 0425 and $0633 \mathrm{~h}$, for example, the $0.210 \mathrm{~Hz}$ energy decreased substantially, whilst the $0.035 \mathrm{~Hz}$ energy increased. However, the combined $0.175+0.210$ $\mathrm{Hz}$ energy does mimick the trends in the 0.035 $\mathrm{Hz}$ band very closely. It is hypothesized that the enormous increase in the $0.175 \mathrm{~Hz}$ energy contributed significantly to the triad resonance during the early period, thereby cascading sufficient energy to the low-frequency motion to cause the observed rise. After $0633 \mathrm{~h}$, both of the incident frequency bands decreased in energy, and a concomitant decline occurred at the $0.035 \mathrm{~Hz}$ frequency. However, another energy increase in the $0.035 \mathrm{~Hz}$ band occurred between 0922 and $1200 \mathrm{~h}$, despite the minor decrease in the $0.175 \mathrm{~Hz}$ energy. It would appear that the increase in the $0.210 \mathrm{~Hz}$ energy during this time interval was of sufficient magnitude to overcome the slight decrease in the $0.175 \mathrm{~Hz}$ energy, and thus, energy was again cascaded to the lower frequency wave of the triad. This suggests that the growth and decay of the $0.035 \mathrm{~Hz}$ motion depended on the interaction of the two incident waves when both were at fairly energetic levels, rather than on the trends of the individual motions alone. Although there are no obvious means by which to validate this hypothetical resonance condition, it is clearly not necessary to invoke topographic controls as the basis for the existence of the $0.035 \mathrm{~Hz}$ motion.

\section{Morphological response}

The bathymetry of the experimental area before and after the June 1-2 storm is shown in 
Fig.15. On May 28, the nearshore bar features were essentially linear. After the storm, the most pronounced changes appeared between $30 \mathrm{~m}$ and $60 \mathrm{~m}$ offshore. A deep hollow was scoured $45 \mathrm{~m}$ offshore along the instrument array (close to the location of WW03). Similar scour hollows appeared just to the north of M4 and to the south of M1 (see Fig.2 for locations). In addition, the middle bar became rhythmic with the crestal distance undulating between approximately $52 \mathrm{~m}$ and $58 \mathrm{~m}$ offshore. A subtle onshore migration of the bar was also measured. Interestingly, the configuration of the shoreline remained essentially linear.
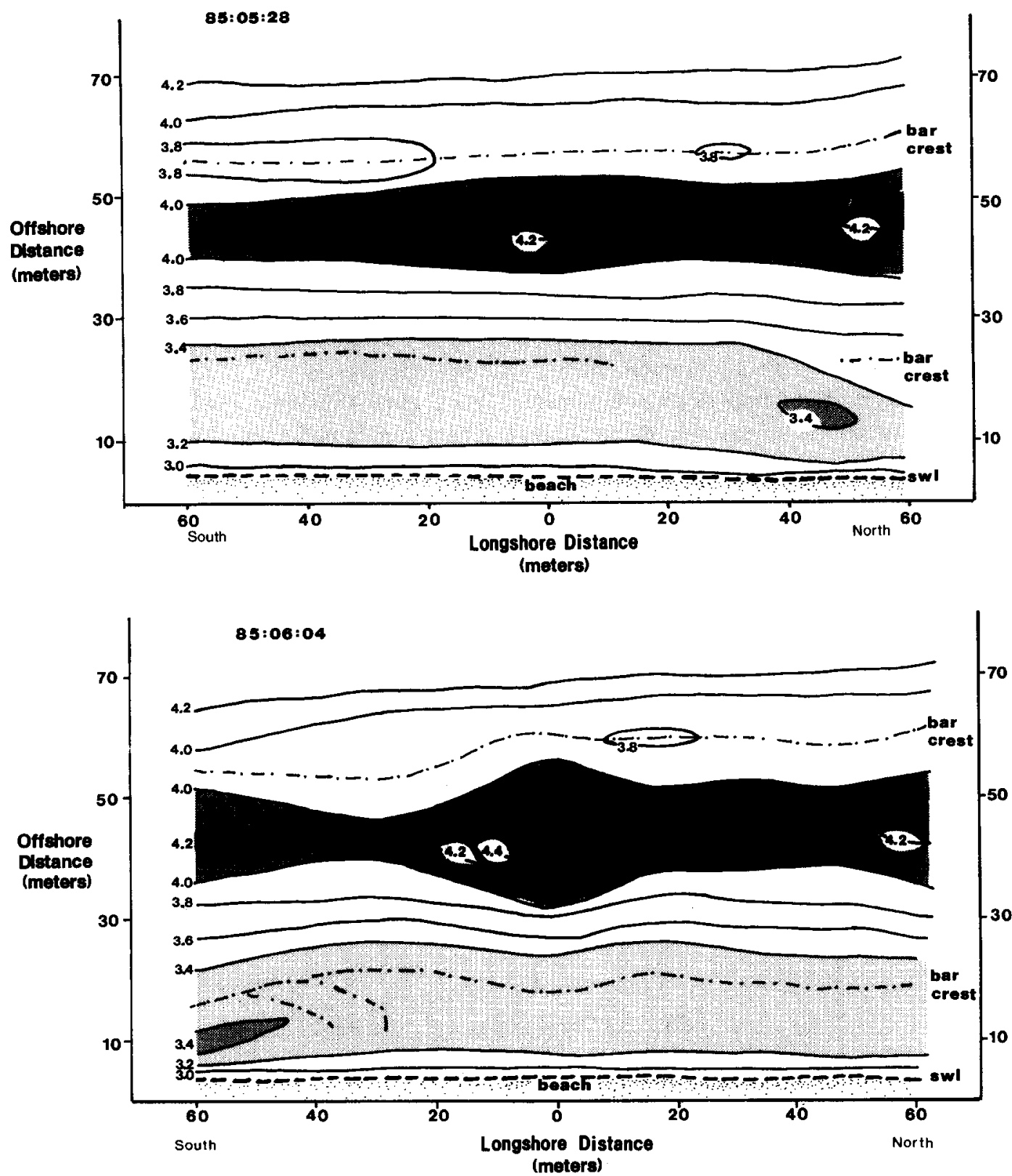

Fig.15. Pre- and post-storm (top and bottom respectively) bathymetry for the June 1-2 storm. Note the marked change from a linear configuration to one that is undulatory. Depth contours in meters. 
Determining the bathymetry that would be in equilibrium with a wave field which includes edge wave motion is a difficult undertaking, as discussed by Holman and Bowen (1982). For standing wave forms, many researchers have suggested that zones of sediment convergence are associated with surface elevation antinodes (e.g., Carter et al. 1973; Short, 1975; Bowen, 1980; Kirby et al., 1981; Symonds and Bowen, 1984; Wright et al., 1986). The drift velocities in the bottom boundary layer are cellular, and there is a horizontal divergence of fluid away from nodal lines and towards antinodal lines in the upper parts of these cells. Therefore, suspended sediment transport should result in an accumulation of sediment under antinodes, and hence form bar crests. In many barred nearshores, the average grain size in troughs is coarser than on bar slopes or bar crests (Greenwood and Davidson-Arnott, 1975, 1979; Davidson-Arnott and Greenwood, 1976).

If it is accepted that suspended sediments will accumulate below antinodes of surface elevation, then a comparison of the nodal pattern of the $0.035 \mathrm{~Hz}$, mode 3, standing edge wave presented in Fig.12 with the bathymetry of May 28 and June 4 (Fig.15) proves rather interesting. The locations of the bar crests and troughs, identified from the profiles, coincide reasonably well with the antinodal and nodal lines of the edge wave respectively. Note, however, that the correspondence is far from perfect, especially for the middle bar (centered around $56 \mathrm{~m}$ offshore). This is of considerable relevance in assessing the role of the edge wave motion in the evolution of the June 4 bathymetry. Figure 12 shows that the antinodal and nodal lines at $50.2 \mathrm{~m}$ and $31.4 \mathrm{~m}$, respectively, were positioned slightly shoreward of the crest and trough of the middle bar, even on June 4 after the storm had passed. This suggests that the onshore migration of the bar form during the storm may have been forced by the edge wave.

Figure 16 shows the net elevation changes between May 28 and June 4 for a few offshore
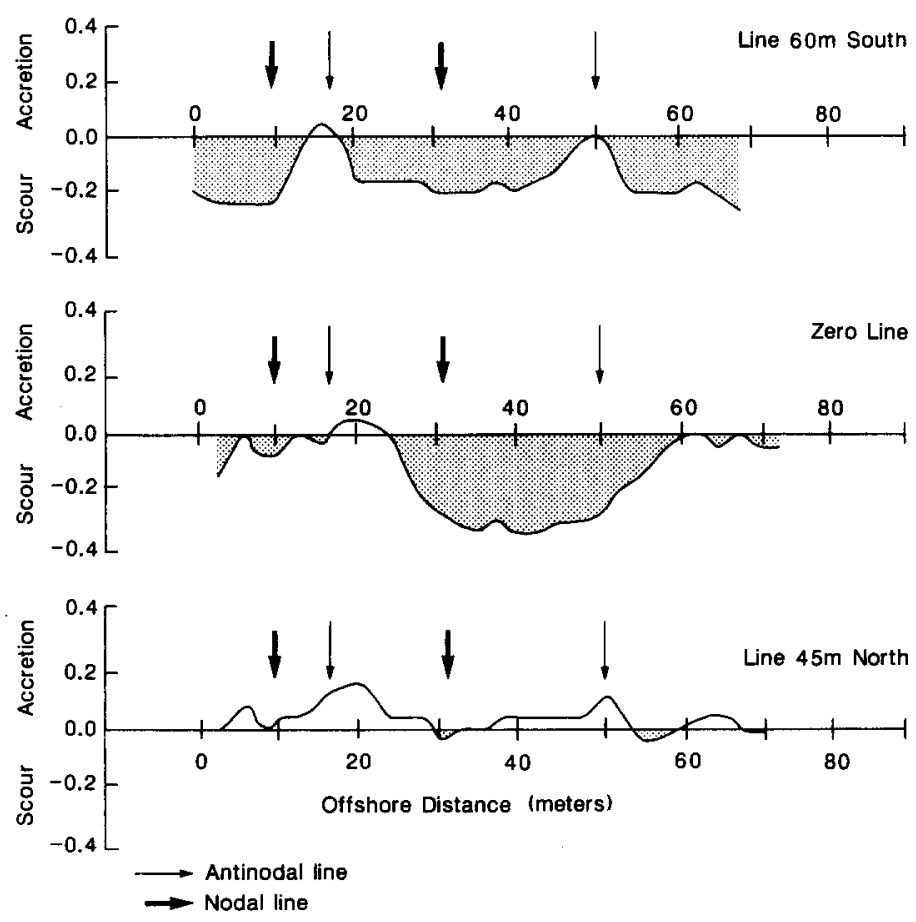

Fig.16. Net elevation changes along selected offshore profile lines as a result of the June 1-2 storm. Stipple indicates scour. Offshore nodal and antinodal positions for the $0.035 \mathrm{~Hz}$ standing edge wave are indicated by the vertical arrows. 
profile lines. The location of the offshore antinodal and nodal lines are indicated on these profiles, and there is an obvious association with zones of accretion and scour, respectively. Indeed, the fit is much better for these zones of net elevation change than for the actual bar crest and trough locations. It should be noted that a similar cross-shore pattern could have been produced without standing edge waves in the wave field. The interaction of an incident, shore-normal, standing gravity wave with a progressive edge wave, for example, could have the same offshore nodal structure. However, a standing edge wave should, in addition, produce alongshore rhythmicity as well as the offshore rhythmicity shown. Figure 15 shows that after the June 1-2 storm, the middle bar crest displayed undulations and that there was a distinct alongshore pattern of scour and accretion, which was in contrast to the linear features prior to the storm (May 28). The unequal distribution of scour and accretion in the alongshore direction is most evident in Fig.16. At $60 \mathrm{~m}$ south of the instrument array and along the instrument array (zero line), there were subsantial sediment losses: 10.950 and $10.475 \mathrm{~m}^{3}$ per unit profile width for these lines, respectively. The profile at $45 \mathrm{~m}$ north of the instrument array, on the other hand, gained $2.900 \mathrm{~m}^{3}$ per unit profile width of sediment during this period. Alongshore sediment flux divergence is not easily explained by incident standing wave motion or by progressive edge wave motion alone. Standing edge wave motion explains the observed pattern satisfactorily.

\section{Discussion}

Most landscapes have "memory"; i.e., they do not respond instantaneously to imposed forces, and therefore must have a configuration that reflects both past and present forcing conditions (short-term equilibria are not expected). An "equilibrium" topography, for which the length scales match the scales of the fluid motion, would be expected only if the hydrodynamic forcing is maintained for a sufficiently long period of time to produce zero sediment flux divergence across the entire region of interest. Prior to this ideal condition, however, it is more likely that zones of maximum change, rather than the pronounced bathymetric features themselves, correspond most closely with the length scales of the fluid field.

Figure 17 is an idealized mapping of the drift velocities for the $0.035 \mathrm{~Hz}$ standing edge wave. The lengths of the arrows are not proportional to the velocity magnitudes, but give an indication of the general trends only. Of particular interest are the locations marked by dots, which correspond to zones of zero orbital velocity and zero drift velocity. The largest dots mark the crossing of antinodal lines where there is strong convergence of the drift vectors. Sediment accumulation is expected to be most pronounced at these locations. The smaller dots mark the crossing of nodal lines, where the sedimentary response is not as pronounced. Bowen and Inman (1971) suggested that crescentic forms would appear in the presence of standing edge waves, with horns at these smaller dots and the crest line arcing offshore towards the larger dots. Scour would be most evident in intermediate locations, especially along nodal lines.

Also plotted on Fig.17 are the zones of greater than $0.10 \mathrm{~m}$ of accretion and scour that occurred in response to the June 1-2 storm. Although the crescentic forms predicted by theory do not appear on the bathymetric map of June 4 (Fig.15), the zones of pronounced change seem to correspond to the drift patterns associated with the $0.035 \mathrm{~Hz}$ standing edge wave. This is most evident for the zones of accretion. Within the vicinity of three of the four large dots are elongated zones of greater than $0.10 \mathrm{~m}$ of sediment accumulation due to aggradation on the landward slopes of the bars. On the bathymetric map of June 4 (Fig.15) these zones can be identified by crenulations in the bar crests and associated contour lines. In the vicinity of the fourth large dot in Fig.17, aggradation was manifest by the bifurcating crestline of the inner bar shown in Fig.15 


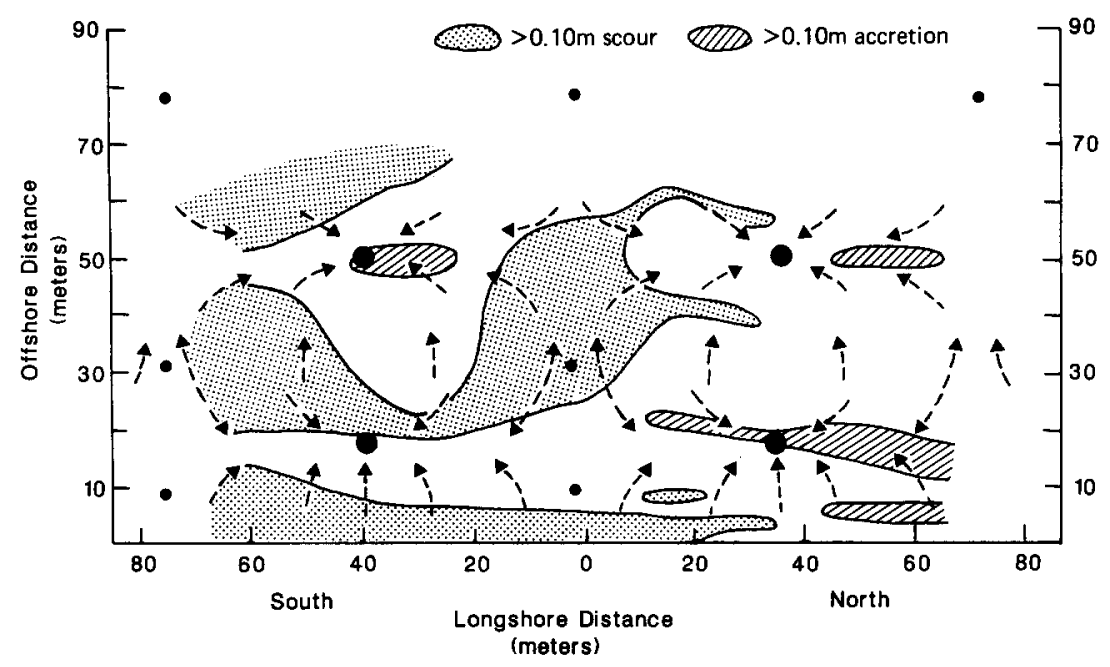

Fig.17. Generalized drift velocity pattern associated with the $0.035 \mathrm{~Hz}$ standing edge wave shown in Fig.12. Dots indicate regions where orbital and drift velocities are both zero. Large dots indicate regions where antinodal lines cross, and where sediment accretion is expected to be most pronounced. Stippled areas indicate zones of greater than $0.10 \mathrm{~m}$ of scour. Shaded areas indicate zones of greater than $0.10 \mathrm{~m}$ of accretion. Refer to Fig. 15 for more details of the bathymetric changes.

(15-20 $\mathrm{m}$ from the baseline, along the $40 \mathrm{~m}$ south profile line).

At the shoreline, the drift vectors are directed offshore, and a long, thin zone of scour extends across a major part of the experimental area. This explains why the configuration of the shoreline remained essentially linear even though the bathymetry only $15 \mathrm{~m}$ lakeward, and beyond, became rhythmic. Similarly, the drift velocities along the zero profile line are directed away from the nodal line at $2 \mathrm{~m}$ south, and therefore, a net sediment loss is expected along the zero line. The pronounced scour hollow that developed along the zero line (Figs.15, 16 and 17) is consistent with this expectation. Similar scour hollows appear immediately to the north and south of the experimental site approximately $40-45 \mathrm{~m}$ offshore from the baseline (delineated by the semi-circular $4.2 \mathrm{~m}$ depth contours in Fig.15). These hollows would appear to be related to the alongshore nodal lines of the standing wave form immediately outside the experimental region at $75.5 \mathrm{~m}$ south and $71.5 \mathrm{~m}$ north. Conversely, the offshore region, at distances greater than $80 \mathrm{~m}$ from the baseline, experienced no net elevation change throughout the entire 2 month period of the study despite sediment reactivation depths of up to $0.08 \mathrm{~m}$. Apparently the standing edge wave did not cause an ordered pattern of sediment redistribution in deeper water because of the rapid offshore energy decay characteristic of lower mode edge waves.

It is clear that the zones of maximum accretion and scour that developed as a result of the June 1-2 storm coincided reasonably well with the hypothesized zones of drift velocity convergence and divergence respectively. Unfortunately, the crescentic forms predicted by theory did not evolve. It is thought that such forms could have developed had the hydrodynamic forcing been maintained for a longer period of time. However, in order to reshape the pre-existing linear bartrough morphology, a substantial volume of sediment would have had to have been redistributed. The development of equilibrium crescentic forms was hampered further by the net sediment removal from the experimental area during this storm. Figures 16 and 17 show that this loss was not equally distributed in the alongshore direction; the southern part of the experimental site lost much more sediment than the northern part. So even though Holman and Bowen (1982) demonstrated that the 
drift patterns associated with various combinations of edge wave modes looked remarkably similar to certain nearshore topographic features, the manner in which such a pattern manifests itself in the real world under less than ideal conditions is not necessarily evident.

\section{Conclusions}

There has been considerable debate about the manner in which nearshore bars evolve. This study of the detailed fluid and sediment motions at Wymbolwood Beach indicates the viability of the postulates of Bowen and Inman (1971) and Holman and Bowen (1982), and reinforces the observations of many others regarding the potential importance of lowfrequency motions to nearshore hydrodynamics.

The conclusion that a standing edge wave of mode 3 or greater in the frequency range centered around $0.035 \mathrm{~Hz}$ existed during the June 1-2 storm was based on the following evidence:

(1) The energy spectra from the cross-shore array of wave staffs showed a persistent, lowfrequency peak centered at $0.035 \mathrm{~Hz}$ that was especially pronounced during the most energetic parts of the storm, and for a substantial period of time thereafter.

(2) The offshore decay of the $0.035 \mathrm{~Hz}$ energy was complex, and the offshore trend could not be explained reasonably by an edge wave profile with mode less than 3 .

(3) Cross-spectral analysis of the fluid motion in the three cardinal directions from colocated instruments showed consistency with the expected phases for a standing edge wave throughout the storm.

(4) Cross-spectral analysis across the alongshore array of wave staffs also showed the $0.035 \mathrm{~Hz}$ motion to be standing in the shoreparallel direction with an approximate wavelength of $150 \mathrm{~m}$.

(5) Solution of the governing equations using an average plane beach slope, and assuming the edge wave was of mode 3 , yielded a shore-parallel wavelength of $147 \mathrm{~m}$, in excellent agreement with the spatially lagged crossspectral analysis.

The hypothesis that the standing edge wave motion centered around $0.035 \mathrm{~Hz}$ played a major role in the redistribution of sediments during this storm is supported by the reasonably close association between the length scales of the edge wave and those of the observed morphological response. The locations of maximum aćcretion coincided with the offshore locations of surface elevation antinodes as predicted using analytical solutions for a plane beach. There have been divergent viewpoints as to whether sediments accumulate under nodes or antinodes of standing waves due to the dominance of bedload or suspended load transport, respectively (Carter et al., 1973; Lau and Travis, 1973; Bowen, 1980). Much of the empirical evidence of late suggests that bars tend to form under surface elevation antinodes (e.g., Huntley, 1980a; Wright et al., 1986; Sallenger and Holman, 1987), and the findings of the present study also support this hypothesis. In addition, the average sediment size at the Wymbolwood Beach site is almost always finer on the bar crests than in the troughs, implying a suspended-sediment-dominated transport system.

At present, there are no viable alternative models that can account for the development of the rhythmicity of the middle bar-trough system while, at the same time, maintaining the linearity of the shoreline and the equilibrium configuration of the offshore region. In the presence of progressive edge waves or incident standing waves, for example, a predominantly linear pattern should evolve everywhere with the linearities trending in the alongshore direction. The equilibrium crescentic forms under standing edge waves predicted by theory did not evolve during this storm, perhaps, because the hydrodynamic forcing was not maintained for a sufficiently long period of time and because sediments were being lost from the experimental site while being rearranged.

The goodness-of-fit (or lack or it) between the 
length scales of the fluid motion and the nearshore bathymetry is often used as evidence in support of (or against) a model. It was suggested by Huntley (1980a), that: "...the definitive field experiment, measurement of the nearshore velocity field during the formation of a predicted rhythmic topography, will probably have to rely on serendipity...". We would argue that the difficulties lie, in large part, in determining the manner in which a predicted topography manifests itself in the nearshore. The development of equilibrium nearshore forms, such as those produced by computer models under the conditions of zero net sediment flux divergence, is probably unrealistic for natural environments. Indeed, Holman and Bowen (1982) state explicitly the difficulties of establishing reasonable modeling topographies and the transfer of these concepts to the prototype. Furthermore, there are considerable problems with lag effects in the response of the sediment transport system to imposed hydrodynamic forces, with inherited morphologic features from previous events, and in marine systems, with tidal fluctuations. If nonequilibrium forms are the norm, more attention should be focused on patterns of scour and accretion and their relationship to the wave motions that produced them.

\section{Acknowledgements}

Debts of gratitude are due to Douglas Sherman and Andrew Hincenbergs without whom this project would not have been possible. The field experiments were funded by the Natural Sciences and Engineering Research Council Canada through operating grant A7956 and equipment grant E6614 to BG. Further financial assistance to $\mathrm{BB}$ was provided by an NSERC Postgraduate Scholarship and a Johns Hopkins University Fellowship. Thanks also to Karl Weisser and his staff in the Academic Workshops, to the Electronics Workshop staff, to $\mathrm{Liz}$ and the people in the Graphics Department, all from Scarborough Campus, University of Toronto, and to the reviewers for providing insightful and constructive criticism.

\section{References}

Aubrey, D.G. and Trowbridge, J.H., 1985. Kinematic and dynamic estimates from electromagnetic current meter data. J. Geophys. Res., 90 (C5): 9137-9146.

Aubrey, D.G. and Trowbridge, J.H., 1988. Reply: Comment on "Kinematic and dynamic estimates from electromag. netic current meter data" by R.T. Guza. J. Geophys. Res., 93 (C2): 1344-1346.

Aubrey, D.G., Spencer, W.D. and Trowbridge, J.H., 1984. Dynamic response of electromagnetic current meters. Tech. Rep. WH01-84-20, CRC-84-3, 150 pp.

Bauer, B.O. 1988. Nearshore morphodynamics and the relative role of low frequency wave motion. Thesis, The Johns Hopkins University, Baltimore, Md, 270 pp.

Boczar-Karakiewicz, B., Bona, J.L. and Cohen, D.L. 1986. Interaction of shallow-water waves and bottom topographies. In: Dynamical Problems in Continuum Physics. Springer, Berlin, Vol.4, pp.131-176.

Bowen, A.J., 1967. Rip currents. Thesis, Univ. California, San Diego, 115 pp.

Bowen, A.J., 1969. Rip currents. 1. theoretical investigations. J. Geophys. Res., 74: 5467-5478.

Bowen, A.J., 1980. Simple models of nearshore sedimentation; beach profiles and longshore bars. In: S.B. McCann (Editor), The Coastline of Canada. Geol. Surv. Can., Pap., 80(10): 1-11.

Bowen, A.J. and Guza, R.T., 1978. Edge waves and surf beat. J. Geophys. Res., 83 (C4): 1913-1920.

Bowen, A.J. and Huntley, D.A., 1984. Waves, long waves, and nearshore morphology. In: B. Greenwood and R.A. Davies, Jr. (Editors), Hydrodynamics and sedimentation in wave-dominated coastal environments. Mar. Geol., 60: $1-13$.

Bowen, A.J. and Inman, D.L., 1971. Edge waves and crescentic bars. J. Geophys. Res., 76: 8662-8671.

Carter, T.G., Liu, P.L.F. and Mei, C.C., 1973. Mass transport by waves and offshore sand bedforms. ASCE J. Waterw. Harbors. Coastal Eng. Div., WW2, 99: 165-184.

Culley, S.K. and Holman, R.A., 1985. Long waves trapped on a pocket beach. EOS, Trans. Am. Geophys. Union, 66 (46): 919.

Cunningham, P.M., Guza, R.T. and Lowe, R.L., 1979. Dynamic calibration of electromagnetic flow meters. In: Proc. Oceans '79. IEEE, New York, pp.298-301.

Cushing, V., 1976. Electromagnetic water current meter. In: Proc. Oceans '76. IEEE and MTS, pp.25C-1-25C-17.

Dally, W.R., 1987. Longshore bar formation - surf beat or undertow. In: Proc. Specialty Conference on Advances in Understanding of Coastal Sediment Processes, Coastal Sediments '87. Am. Soc. Civ. Eng., Vol.1, pp.71-86.

Davidson-Arnott, R.G.D. and Greenwood, B., 1976. Facies relationships on a barred coast, Kouchibouguac Bay, New Brunswick, Canada. In: R.A. Davies and R.L. Ethington (Editors), Beach and Nearshore Sedimenta- 
tion, Soc. Econ. Paleontol. Mineral. Spec. Publ., 24: 140-168.

Davidson-Arnott, R.G.D. and McDonald, R.A., 1989. Nearshore water motion and mean flows in a multiple parallel bar system. Mar. Geol., 86: 321-338.

Dixon, W.J. (Editor), 1985. BMDP Statistical Software, 1985. Univ. California Press, Los Angeles, 734 pp.

Doering, J.C. and Bowen, A.J., 1987. Skewness in the nearshore zone: a comparison of estimates from MarshMcBirney current meters and colocated pressure sensors. J. Geophys. Res., 92 (C12): 13,173-13,183.

Eckart, C., 1951. Surface waves in water of variable depth. Scripps Inst. Oceanogr. Wave Rep. 100, Ref. 51-12.

Galvin, C.J., 1965. Resonant edge waves on laboratory beaches. EOS, Trans. Am. Geophys. Union, 46 (1): 112.

Greenwood, B. and Davidson-Arnott, R.G.D., 1975. Marine bars and nearshore sedimentary processes, Kouchibouguac Bay, New Brunswick, Canada. In: J.R. Hails, and A. Carr (Editors), Nearshore Sediment Dynamics and Sedimentation. Wiley, New York, pp.123-150.

Greenwood, B. and Davidson-Arnott, R.G.D., 1979. Sedimentation and equilibrium in wave-formed bars: a review and case study. Can. J. Earth Sci., 16: 312-332.

Greenwood, B. and Sherman, D.J., 1983. Shore-parallel flows in a barred nearshore. Proc. Conf. Coastal Engineering, 18th. Am. Soc. Civ. Eng., New York, pp.1677-1696.

Greenwood, B. and Sherman, D.J., 1984. Waves, currents, sediment flux and morphological response in a barred nearshore system. Mar. Geol., 60: 31-61.

Guza, R.T., 1988. Comment on "Kinematic and Dynamic Estimates From Electromagnetic Current Meter Data" by D.G. Aubrey and J.H. Trowbridge. J. Geophys. Res., 93 (C2): 1337-1343.

Guza, R.T. and Bowen, A.J., 1975. The resonant instabilities of long waves obliquely incident on a beach. J. Geophys. Res., 80: 4529-4534.

Guza, R.T. and Bowen, A.J., 1976. Finite amplitude edge waves. J. Mar. Res., 34: 269-293.

Guza, R.T. and Bowen, A.J., 1977. Resonant interactions for waves breaking on a beach. In: Proc. Conf. Coasal Engineering, 15th. Am. Soc. Siv. Eng., New York, pp.560-579.

Guza, R.T. and Inman, D.L., 1975. Edge waves and beach cusps. J. Geophys. Res., 80: 2997-3012.

Guza, R.T. and Thornton, E.B., 1985. Observations of surf beat. J. Geophys. Res., 90 (C2): 3161-3172.

Guza, R.T., Clifton, M.C. and Rezvani, F., 1988. Field intercomparison of electromagnetic current meters. J. Geophys. Res., 93: 9302-9314.

Harris, T.F.W., 1967. Field and model studies of the nearshore circulation. Thesis, Univ. Of Natal, Durban. $188 \mathrm{pp}$.

Holman, R.A. and Bowen, A.J., 1979. Edge waves on complex beach profiles. J. Geophys. Res., 84: 6339-6346.

Holman, R.A. and Bowen, A.J., 1982. Bars, bumps and holes: models for the generation of complex beach topography. J. Geophys. Res., 87 (C1): 457-468.

Holman, R.A. and Bowen, A.J., 1984. Longshore structure of infragravity wave motions. J. Geophys. Res., 89 (C4): 6446-4652.
Holman, R.A., Huntley, D.A. and Bowen, A.J., 1979. Infragravity waves in storm conditions. Proc. Conf. Coastal Engineeering, 16th. Am. Soc. Civ. Eng., New York, pp.268-284.

Huntley, D.A., 1976. Long-period waves on a natural beach. J. Geophys. Res., 81 (36): 6441-6449.

Huntley, D.A., 1980a. Edge waves on a crescentic bar system: In: S.B. McCann (Editor), The Coastline of Canada. Geol. Surv. Can., Pap., 80 (10): 1-11.

Huntley, D.A., 1980b. Electromagnetic flow meters in nearshore field studies. In: Workshop on Instrumentation for Currents and Sediments in the Nearshore Zone. Assoc. Comm. Res. Shoreline Erosion and Sedimentation, Natl. Res. Counc. Can., Ottawa, pp.47-60.

Huntley, D.A., Guza, R.T. and Thornton, E.B., 1981. Field observations of surf beat, 1. Progressive Edge Waves. J. Geophys. Res., 86 (67): 6451-6466.

Huntley, D.A. and Kim, C.S., 1984. Is surf beat forced or free? In: Proc. Conf. Coastal Engineering, 19th. Am. Soc. Civ. Eng., New York, pp.871-885.

Isaacs, J. D., Williams, E.A. and Eckart, C., 1951. Total reflection of surface waves by deep water. Trans. Am. Geophys. Union, 32: 37-40.

Julian, P.R., 1975. Comments on the determination of significance levels of the coherence statistic. J. Atmos. Sci., 32: 836-837.

Kalvaitis, A.N., 1977. Current sensor dynamic testing. Polymode News, 28.

Katoh, K., 1981. Analysis of edge waves by means of empirical eigenfunctions. Rep. Port Harbour Res. Inst., J. Minist. Transp., 20 (3), 3 pp.

Kim, C.S. and Huntley, D.A., 1986. On time delays in the nearshore zone between onshore and longshore currents at incident wave frequencies. J. Geophys. Res., 91 (C3): 3967-3978.

Kirby, J.T., Dalrymple, R.A. and Liu, P.L.F., 1981. Modification of edge waves by barred-beach topography. Coastal Eng., 5: 35-49.

Lau, J. and Travis, B., 1973. Slowly varying Stokes waves and submarine longshore bars. J. Geophys. Res., 78: 4489-4497.

Middleton, J.H., Cahill, M.L. and Hsieh, W.W., 1987. Edge waves on the Sydney coast. J. Geophys. Res., 92 (C9): 9487-9493.

Munk, W.H., Snodgrass, F., and Gilbert, F., 1964. Long waves on the continental shelf: an experiment to separate trapped and leaky modes. J. Fluid Mech., 20 (4): 529-554.

Oltman-Shay, J. and Guza, R.T., 1987. Infragravity edge wave observations on two California beaches. J. Phys. Oceanogr., 17: 644-663.

Phillips, O.M., 1977. The Dynamics of the Upper Ocean. Cambridge Univ. Press, London.

Sallenger, A.H. and Holman, R.A., 1985. Wave energy saturation on a natural beach of variable slope. J. Geophys. Res., 90 (C6): 11939-11944.

Sallenger, A.H. and Holman, R.A., 1987. Infragravity waves over a natural barred profile. J. Geophys. Res., 92 (C9): 9531-9540. 
Short, A.D., 1975. Multiple offshore bars and standing waves. J. Geophys. Res., 80: 3838-3840.

Stive, M.J.F. and Battjes, J.A., 1985. A model for offshore sediment transport. In: Proc. Conf. Coastal Engineering, 19th. Am. Soc. Civ. Eng., New York, pp.1420-1437.

Stokes, G.G., 1846. Report on recent research in hydrodynamics. Br. Assoc. Adv. Sci. Rep., Pap. i 167.

Symonds, G. and Bowen, A.J., 1984. Interactions of nearshore bars with incoming wave groups. J. Geophys. Res., 89 (C2): 1953-1959.
Thompson, R., 1979. Coherence significance levels. J. Atmos. Sci., 30: 2020-2021.

Truxillo, S.G., 1970. Development of a resistance-wire gauge for shallow-water wave and water level investigations. Coastal Stud. Inst., Louisiana State Univ., Baton Rouge (Unpubl).

Ursell, F., 1952. Edge waves on a sloping beach. Proc. R. Soc. London, Ser. A., 214: 79-97.

Wright, L.D., Nielsen, P., Shi, N.C. and List, J.H., 1986. Morphodynamics of a bar-trough surf zone. Mar. Geol., 70: 251-285. 